Fig. 3. Eine Pyramidenzelle mit in der Nekrose begriffenem Kern: er bat fast vollständig sein Chromatin verloren, ist homogen, blass, das Kernkörperchen ist kaum unterscheidbar; der Zellkörper ist körnig.

Fig. 4. Ein weiteres Veränderungsstadium der Nervenzelle bei der Cholera: die Vacuolen vereinigen sich, indem sie dadurch den ganzen Zellkörper sprengen; das Protoplasma ist sehr grobkörnig geworden; die Fortsätze haben sich abgetrennt und sind auch in Körner zerfallen. Der pericelluläre Raum ist vergrössert. Kern und Kernkörperchen sind unverändert.

Fig. 5. Eine nekrotisirte, körnige Zelle ohne Fortsätze und mit einem, in schwach gefärbte Chromatinkörner zerfallenen Kern.

Fig. 3 bildet nicht den Uebergang von Fig. 2 zu Fig. 4.

\title{
III.
}

\section{Untersuchungen über die käsige Nekrose tuberculösen Gewebes.}

(Aus dem Pathologischen Institut der Universität München.)

\author{
Von Dr. Hans Schmaus, \\ Privatdocenten und I. Assistenten am Pathologischen Institut, \\ und Dr. Eugen Albrecht in München.
}

(Hierzu Taf. II und III.)

Die im Folgenden mitgetheilten Untersuchungen bilden die Fortsetzung unserer Studien über Nekrose, welche wir im vorigen Jahr in diesem Archiv (Bd. 138 Suppl:) veröffentlicht haben, und wir müssen, um Wiederholungen za vermeiden, im Folgenden öfter auf die genannte Veröffentlichung verweisen. Es sollte das Verhalten der Kerne bei der Verkäsung, und zwar zunächst an Impftuberkeln von Meerschweinchen, näher untersucht werden. Es liegt in der Natur der Sache, dass ausser den Kernen auch die an den übrigen Gewebsbestandtheilen sich einstellenden Veränderungen in das Bereich der Untersuchung gezogen werden mussten.

Bei der Beurtheilung der mikroskopischen Veränderungen der Verkäsung besteht eine Schwierigkeit darin, dass der Be- 

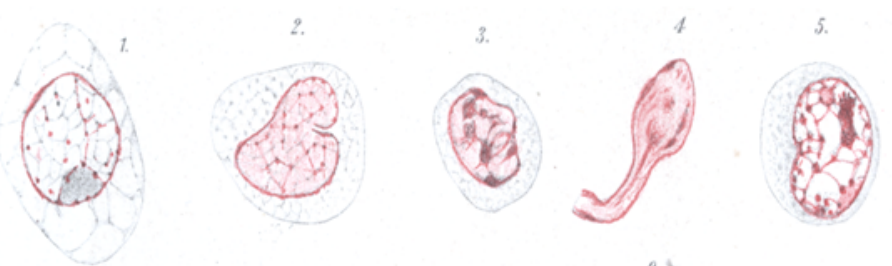

6
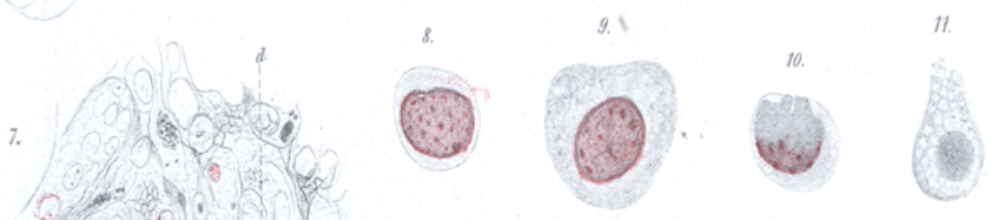
Q.
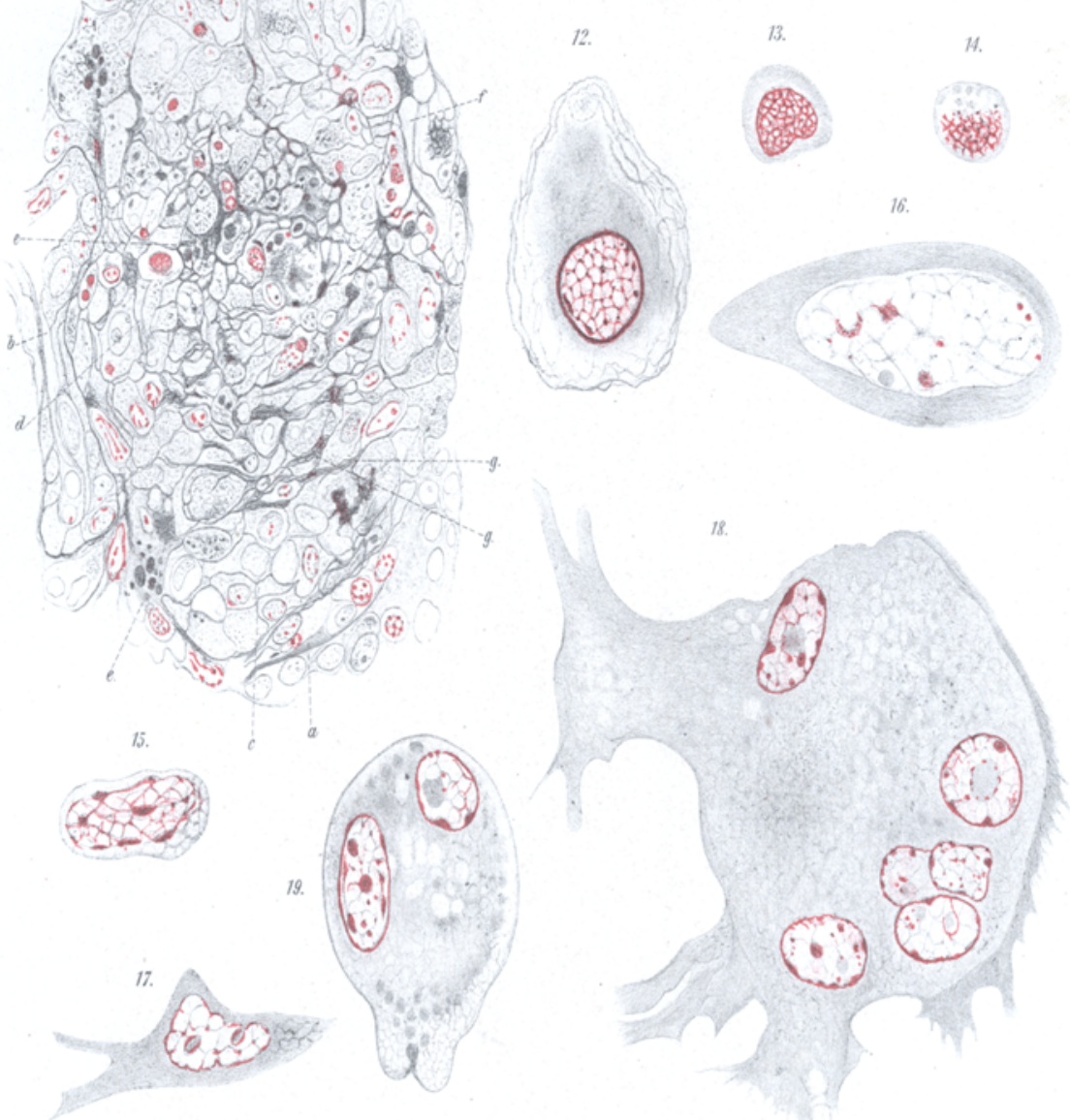

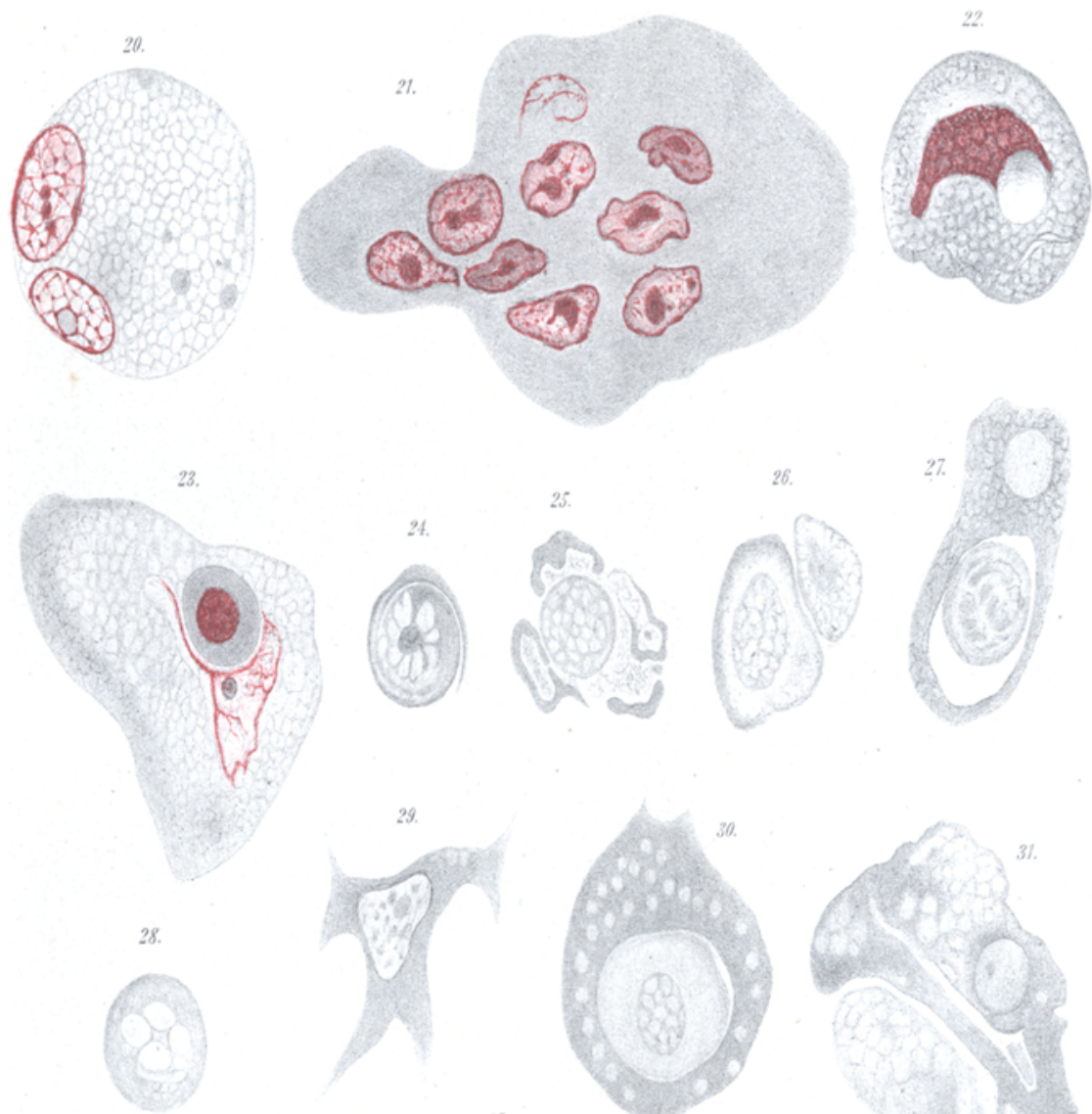

23.
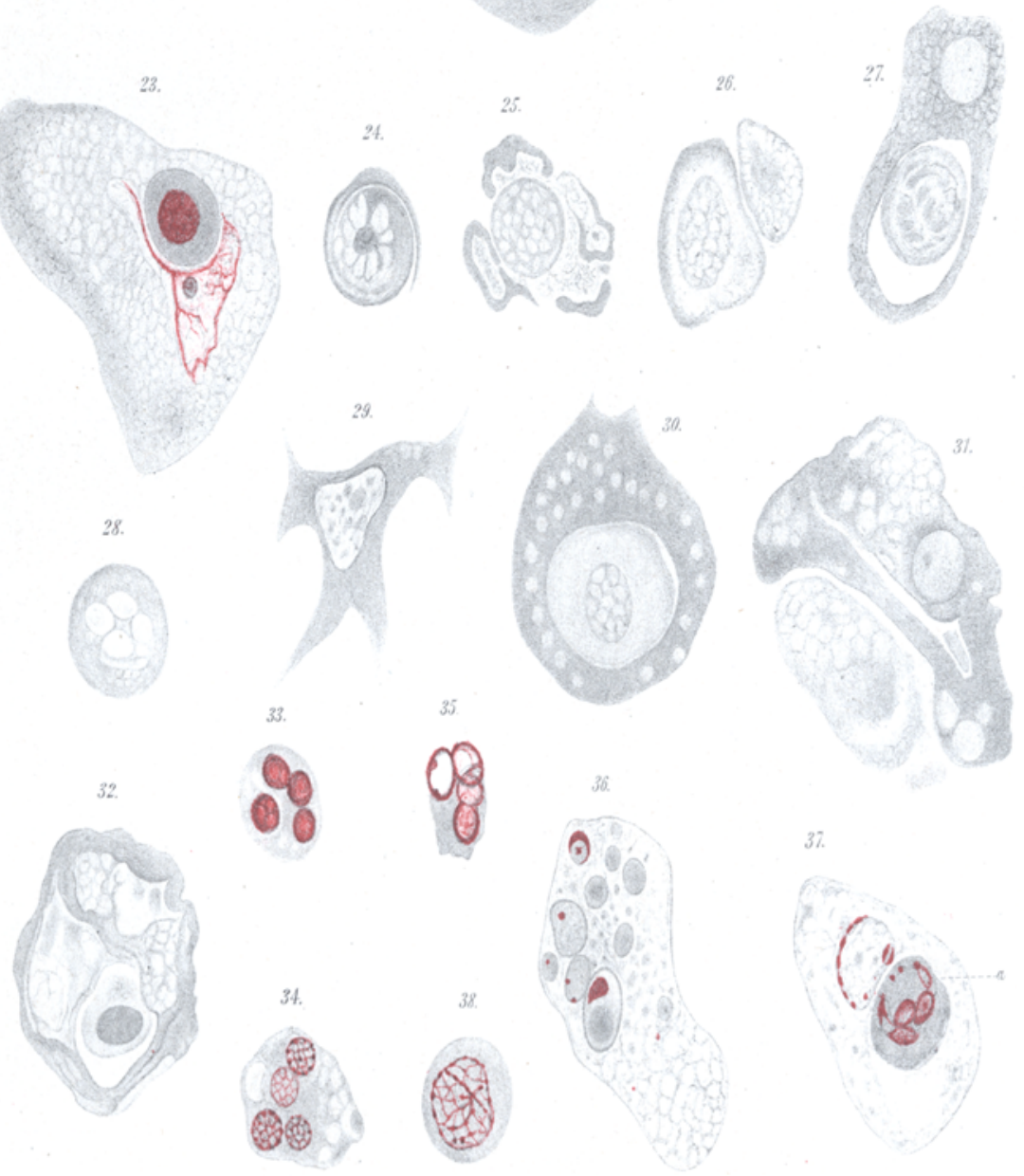

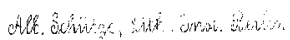


griff dieser Entartung zunächst ein rein makroskopischer ist, und selbst als solcher durchaus nicht scharf begrenzt erscheint, sondern bald enger, bald weiter gefasst wird; werden doch selbst so differente Dinge, wie nekrotische Theile von Tuberkeln oder Gummen und frische anämische Infarkte unter demselben zusammengelasst. Noch weniger besteht eine einheitliche Auffassung der histologischen Veränderungen, und insbesonders ist hier die Grenze gegenüber einfach nekrotischen Theilen, sowie gegenüber hyalinen Produkten eine vielfach schwankende. Ein Kernuntergang, oder doch wenigstens Verlust der Kernfärbbarkeit wird wohl von allen Seiten angenommen, kann aber, nachdem derselbe als allgemeine Erscheinung des Zelltodes anerkannt ist, wohl in keiner Weise für den Begriff der Verkäsung verwerthet werden. Dagegen finden sich vielfach Angaben über ein Zusammensintern der nekrotisehen Zellen neben einer Zerklüftung des todten Materials, und viele Autoren geben einen Zerfall der nekrotischen Massen zu körnigem Detritus geradezu als Merkmal der Verkäsung an; mehrfach ist auch eine stärkere oder geringere Verfettung als wesentliche oder zufällige Begleiterscheinung der Verkäsung erwähnt. Dem gegenüber bezeichnen andere Autoren auch homogene, schollige. Massen als verkäst, setzen also die Bildung eines feinkörnigen Detritus nicht als nothwendiges Merkmal der Verkäsung voraus, wie sie überhaupt eine scharfe Grenze der Verkäsung gegenüber hyalinen Produkten nicht ziehen wollen.

Virchow ${ }^{1}$ ) sieht in der Verkäsung eine unvollständige Fettmetamorphose, welche mit einer Eindickung (Inspissation) verbunden ist. In Folge eines frühzeitig eintretenden Absterbens kommt es zu einem Wasserverlust und einer Schrumpfung der Elemente, da dieselben nicht mehr, wie die lebenden Zellen, im Staude sind, die flüssigen Bestandtheile in sich zurückzuhalten. Die käsige Substanz entspricht also todten Resten zerfallener Gewebssubstanz und zwar handelt es sich theils um fettigen Zerfall, theils um Schrumpfung der Elemente.

Seh äppel 2) bezeichnet die Verkäsung als Umwandlung der Tuberkelelemente in einen molekularen Detritus, welche durch eine partielle, fettige

1) Die krankhaften Geschwülste. Bd. II.

2) Untersuchungen über Lymphdrüsentuberculose. Tübingen 1871. S. 98. 
Degeneration sämmtlicher Formbestandtheile des Tuberkels eingeleitet wird; daneben geht eine Schrumpfung einber, welche auf Wasserentziehung zu beruhen scbeint. Sowohl das Zellplasma, wie das Reticulum des Tuberkels werden trüb, nnregelmässig und zerfallen schliesslich zu feinen Körnchen. Die Kerne bleiben länger erhalten, schrumpfen aber schliesslich ebenfalls und mischen sich dem übrigen Detritus bei.

Arnold!) will als verkäst blos solche Theile bezeichnen, welche makroskopisch als gelbe, bröcklige, trockene Massen sich darstellen und bei der mikroskopischen Untersuchung aus grösseren und kleineren, form- und strukturlosen Bröckeln, denen Fett in grösserer oder geringerer Menge beigemengt ist, sich zusammengesetzt zeigen.

Eine eigenthümliche Anschauung vertritt Vallat ${ }^{2}$ ). Nach ihm kann verkäste Masse zwar auch direct durch einfachen molekularen Zerfall und zwar von einer byalinen Substanz entsteben ("kanalisirtes Fibrin"), in anderen Fällen aber besteht die käsige Masse vorzugsweise aus Kernen, welche freilich ibre Färbbarkeit verloren haben und welche entweder von den in den Maschen zwischen den Balken des kanalisirten Fibrins befindlichen Zellen oder von eingewanderten Leukocyten herstammen. Es handle sich also weder um eine Inspissation im Sinne Virchow's, noch um eine Coagulationsnekrose.

Die Lehre von der Inspissation und die von der Coagulationsnekrose sind die eigentlichen Angelpunkte, um welche die Erklärung der käsigen Nekrose in den meisten Arbeiten sich bewegt. Weigert ${ }^{3}$ ) subsumirt die Verkäsung ebenso, wie die hyaline Entartung, wenigstens den grössten Theil der letzteren, unter den Begriff der Coagulationsnekrose, also die Gerinnung des Zellplasmas selbst, und betont besonders, dass der Begriff der Verkäsung ein rein makroskopischer sei und mit der gesehrumpften Zelle nichts zu thun habe; hyaline Bildung und Verkäsung sind wabrscheinlich nicht zwei principiell verschiedene Vorgänge, sondern es bandle sich um den gleichen Prozess in verschiedenen Stadien der Entwickelung. Auch bei Prozessen, welche sonst zur Verkäsung führen (Tuberculose) und neben solcher können byaline Bilaungen auftreten. Die Form der Erkrankung, welche zu Stande kommt (Fibringerinnung in fädiger Form, ader byaline Gerinnung in homogener Form), hängt wesentlich von der Wirkung und der Menge des Plasmastromes ab, der auf die abgestorbenen Massen einwirkt.

Es entsteht nehmlich nach Weigert Hyalin dann, wenn ein sehr bedeutender Plasmä̈berschuss auf die geronnenen oder gerinnenden Substanzen einwirkt. Dieser Ueberschuss kann

1) Dieses Arehiv. Bd.87. S. 114.

$\left.{ }^{2}\right)$ Dieses Archiv. Bd. 89. S. 193.

3) Doutsche med. Wochenschr. 1885. No.44 und Centralbl. f. allgem. Patb. u. s. w. II. S. 785. 
dadurch gegeben sein, dass der Plasmastrom sehr lange und gründlich einwirkt, was besonders der Fall ist, wenn die Flüssigkeit $\mathrm{zwischen}$ die auseinanderweichenden Theile der Massen hineingelangen kann (wie beim Langhans'schen kanalisirten Fibrin, länger bestehenden Infarkten und manchen Formen der Verkäsung); oder dadurch, dass das Verhältniss zwischen Plasma und den selbst in bedeutender Menge absterbenden Protoplasmamassen auch nur relativ zu Gunsten der Flüssigkeit ist (Rachendiphtherie) oder endlich, dass die Grösse der gerinnenden Substanzklumpen eine sehr geringe ist, wie das der Fall ist, wenn in einem Organ das gefässführende Stroma erhalten bleibt, während die Parenchymzellen absterben, wobei die Flüssigkeit nicht in besonderer Menge vorhanden zu sein braucht (Niereninfarkte, wachsartige Degeneration der Muskeln).

Nit Weigert rechnen auch Birch-Hirschfeld und Neelsen die Verkäsung zur Coagulationsnekrose.

Dem gegenüber nimmt Israelil) für die, „im engeren Sinne käsigen Hassen" als charakteristische Erscheinung einen weiteren Zerfall der nekrotischen Theile an, welcher durch eine Schrumpfung, Inspissation im Sinne Virchow's bedingt ist. So entstehen kleine, bröckelige Eiweissmassen aus den Zellen. Ein Auftreten von Fett ist - worauf auch andere Autoren binweisen - bäufig, gehört aber nicht zum Begriff der Verkäsung. So lange die Umgrenzung der Zellen noch deutlich ist, ist auch nocb keine Verkäsung eingetreten, denn der Begriff der Verkäsung knüpft erst an die geschrumpfte, amorph gewordene Zelle an.

$\mathrm{Ziegle{ } ^ { 2 } )}$ weist besonders darauf hin, dass die makroskopisch als Verkäsung bezeichnete Veränderung nicht imwer in der gleichen Weise entsteht. Der Gewebstod erfolge meist nicht rapid, sondern allmählich, so dass der Prozess mehr den Charakter einer fortschreitenden Degeneration oder einer Nekrobiose trägt; der Vorgang vollzieht sich in der Weise, dass das Gewebe entweder direct ein mehr und mehr bomogenes Aussehen gewinnt und seine Kerne verliert, oder so, dass zuerst bomogene Schollen sich bilden, welche später versehmelzen, oder endlich so, dass zuerst unter Auflösung der vorhandenen Zellen Körner und körnige Fäden erscheinen (Fibrin), die zu einer dichten, homogenen Masse sich zusammenschliessen. Die homogenen Massen können nach und nach durch weitere Utnwandlungen mehr körnig werden. Bei einer weicheren Form der Verkäsung besteht die Hauptmasse aus einem fettig-albuminösen, körnigen oder bröckeligen Detritus. Speciell für den Tuberkel bemerkt $Z$ iegler ${ }^{3}$, dass zuerst die kleinen, runden Zellen

1) Practicum. 1893. S. 145 und Dieses Archiv. Bd. 123.

2) Lehrbuch. Bd. I. S. 189.

3) a. a. 0 . S. 613 . 
zu Grunde gehen, ihre Kerne dabei schrumpfen oder zerbröckeln und sich auflösen; weiterhin sterben aucb die grossen Zellen ab und werden zu glänzenden, hyalinen Schollen. In den Riesenzellen findet sich häufig die von Weigert beschriebene partielle Nekrose.

Rindfleisch nimmt die Weigert'sche Deutung von der Coagulationsnekrose an, bezeichnet aber den Vorgang überhaupt als „fibrinöse Entartung“ (Pathologische Gewebelehre, S. 30); speciell bei der Verkäsung Landelt es sich (a. a. O., S. 123) nm Umwandlung der Zellen in undurchsichtige, körnige, starre und scbarf begrenzte Schollen, an denen mit den üblichen Färbemitteln keine Kerne mehr nachgewiesen werden können. An Schnitten bemerkt man häufig eine faserige Zerklüftung des ganzen Materials; wirbelartig sind diese Fasern um gewisse Punkte im Innern des Käseheerdes gruppirt. Rindfleiseh glaubt, dass hier ein misslungener Versuch zur Bildung von Narbengewebe vorliegt.

Wir beschreiben im Folgenden zunächst jene Veränderungen, welche, im Centrum der Knötchen auftretend, jedenfalls zu einer Nekrose der zelligen Elemente führen und ohne scharfe Grenze zu einer körnigen, detritusartigen Beschaffenheit jener Partien überleiten, ohne im Voraus feststellen zu wollen, von wann ab der ganze Vorgang als Verkäsung bezeichnet werden darf und in wie weit es sich nur um Vorstadien derselben handelt, welche vielleicht gar nicht nothwendig im weiteren Verlauf in wirkliche Verkäsung übergehen müssen. Es fällt damit auch ein gewisser Theil dessen in unsere Betrachtung, was man vielfach als hy aline Umwandlung der Tuberkel benannt hat, während die von Arnold als "epitheloide" bezeichnete Umwandlung ein noch früheres Stadium darstellt, an welches sich keineswegs eine käsige Nekrose nothwendig anschliessen muss, wie auch Arnold ausdrücklich hervorhebt.

Der Beschreibung der bei diesen Prozessen eintretenden Veränderungen müssen wir einige Bemerkungen über die Struktur des jungen, noch nicht verkästen Tuberkels vorausschicken, wie dieselbe sich bei den von uns angewendeten Behandlungsmethoden darstellt. Die eine Bemerkung betrifft das Verhalten einiger Kern- und Zellstruktaren im Tuberkel, die andere das Reticulum desselben und seine Interstitialsubstanz überhaupt.

Was den ersten Punkt betrifft, so müssen hier verschiedene Zellformen unterschieden werden, welche freilich nicht durchweg scharf trennbar sind. Wenigstens in jungen Tuberkeln bilden die Hauptmasse der Zellen die sogenaunten epitheloiden Ele- 
mente, die sich durch einen grossen, rundlichen, ovalen oder auch polygonalen, des öfteren auch mehr oder minder zackigen Zellkörper auszeichnen. Das Protoplasma dieser Zellen, welche in die Maschenräume des Tuberkelreticulums eingelagert sind, enthält mittelgrosse, ziemlich dunkle und regelmässig angeordnete Körner, die aber gegen den Rand zu etwas spärlicher zu sein pflegen, so dass der Zellkörper an seinen äusseren Partien ein helleres Aussehen erhält. Zwischen den Körnern und diese verbindend, finden sich kurze Fäden, welche ihrerseits am Rande der Zellen besonders deutlich hervortreten. Einzelne der oben erwähnten Körner zeigen sich bei Holzessigbehandlung besonders intensiv grau. Eine geringere Zahl solcher Zellen zeigt überwiegend fädige Struktur in Form eines helleren, lockeren Netzwerks (Fig. 1). Die Kerne dieser Zellen sind der Mehrzahl nach ziemlich hell, fast immer gross, oval oder rundlich; mehrfach zeigen sie auch am Rande kleine Einkerbungen. Die Kernwand zeigt hie und da chromatische Einlagerungen, ist aber fast nie continuirlich chromatisch. Im Innern des Kernes (Fig. 1) liegt ein zartes, aber deutliches, achromatisches Netzwerk, welchem chromatische, meist rundliche Körner und Fäden in spärlicher Zahl eingelagert sind. Meist in der Nähe der Wand, oder derselben anliegend, findet sich ein achromatischer Nucleolus, welcher zum Theil ebenfalls mit Chromatin belegt ist.

Mehrfach zeigen sich nun die Kerne solcher grösserer Zellen hyperchromatisch, mit reichlicheren und grösseren Chromatinkörnern im Innern und an der Kernwand, sowie dickeren chromatischen Fäden zwischen den Körnchen; nicht selten erscheinen sie auch diffus roth gefärbt (Safranin). Manchmal zeigt sich in solchen Kernen ein längerer, bandförmiger chromatischer Körper. Ziemlich viele dieser Formen weisen ferner das Bild der $\mathrm{Na}$ cleolus-Auffaserung auf, wie wir es schon früher (a. a. O. S. 16) beschrieben haben und wie es von Podwyssozki, Galeotti und Anderen auch als Vorstadium der mitotischen Theilung angegeben wurde. Auch diese hyperchromatischen Kerne lassen oft Einkerbungen oder Eintiefungen ihrer Wand erkennen.

Die Mitosen, welcbe sich in Tuberkeln, besonders am Rand derselben und am. Uebergang in die Umgebung finden, gehören ebenfalls, so viel wir sehen, solchen Zellen an. Einmal 
fanden wir auch in einer sehr grossen Zelle zwei im Uebergang: zum Ruhestadium begriffene grössere Tochterknäuel liegen (Riesenzellbildung?). Nebenbei sei noch erwähnt, dass einzelne besonders grosse, mässig hyperchromatische Kerne dadurch auffielen, dass in ihrer Mitte eine verschieden tief gehende, manchmal den Kern durchziehende chromatische Querspange vorhanden war, wobei gleichzeitig der Kern an der Stelle, wo die Spange die Kernwand berührțe, eine Einkerbung aufwies, so dass das Bild an dasjenige der directen Kerntheilung erinnerte.

Ebenfalls in grösseren epitheloiden Zellen liegen, aber nicht in allen Taberkeln gleich häufig, feinkörnig hyperchromatische, dabei leicht diffus gefärbte Kerne (Fig. 2). Bei ihnen fehlen gröbere Chromatinkörper fast durchweg, dagegen ist die Kernwand häufig auf grössere Strecken hin oder auch im Ganzen continuirlich chromatisch, öfter auch leicht verdickt. Das Kerninnere weist ein feines, achromatisches Netzwerk auf, das mit, den zahlreichen, feinen, chromatischen. Körnchen belegt ist. Meistens zeigt die Kernwand zahlreiche, sehr feine, zittrige Einkerbungen, oder auch grössere Eintiefungen der Oberfläche.

Manche der in epitheloiden Zellen gelegenen Kerne endlich zeigen nur eine mehr oder minder starke Verdickung der chromatischen Kerumembran, ohne dass eine Chromatinvermehrung im Innern des Kerns wahrnehmbar wäre.

Schon in ganz frischen, noch reichlicher aber in etwas grösseren Knötchen liegen ausserdem in reichlicherer Zahl kleinere Zellen, und zwar ziemlich unregelmässig in den Maschenräumen des Reticulums eingestreut. Sie besitzen nur einen schwach entwickelten, oft schwer sichtbaren Plasmahof, dagegen sehr dunkle chromatinreiche Kerne. Die meisten dieser Kerne sind im Ganzen rundlich oder oval, sehr häufig aber eingekerbt, eingeschnürt oder sogar deutlich gelappt (Fig. 3). Die Kernwand ist continuirlich chromatisch, mit dicken Körnern versehen. Im Kerninneren finden sich meist ebenfalls reichlich chromatische, abgesetzte Körner, welche unter sich und mit denen der Kernwand durch färbbare Fäden verbunden sind. Wo der Kern im Ganzen eine ovale Gestalt hat, zeigen die Chromatinkörper oft eine seiner Längsaxe entsprechende Anordnung. Endlich zeigen die meisten dieser Kerne eine mehr oder weniger ausgesprochene 
Diffusfärbung. Diese Zellen bilden wohl die Mehrzahl der für gewöhnlich als lymphoide Elemente bezeichneten Tuberkelzellen. Auch konnten wir in Gefässen in der Nähe von Tuberkeln Anhäufung solcher Zellen nachweisen.

Gleichfalls unregelmässig eingelagert finden sich häufig sonst ähnliche Zellen, welche aber durch einen auffallend langen, oft gebogenen, bisquitförmig eingeschnürten, verschieden dicken, am Ende wieder manchmal angeschwollenen oder mit Fortsätzen versehenen Kern ausgezeichnet sind (Fig. 4). Auch diese Kerne sind meistens diffus gefärbt und zeigen sehr ausgesprochen die oben erwähnte Eigenthümlichkeit in der Anordnung ihrer länglich geformten Chromatinkörner, welche fast regelmässig der Längsaxe des Kernes entsprechend orientirt sind. Im Uebrigen gleichen diese Kerne vollkommen den vorhin beschriebenen, mit denen sie durch zahlreiche Uebergangsformen verbunden sind.

Endlich finden sich in Tuberkeln, und zwar meist in verhältnissmässig kleinen Zellkörpern liegend, rundliche oder leicht eingekerbte hyperchromatische Kerne mit dickeren, reichlichen, chromatischen Fäden und Körnern, welche mit den hyperchromatischen Kernen der epitheloiden Zellen grosse Aehnlichkeit aufweisen and oft nicht sicher von solchen unterschieden werden können, die aber andererseits alle Uebergänge zu den kleinen runden Kernen der lymphoiden Elemente aufweisen (Fig. 5, 6).

Die Kerne der Riesenzellen zeigen im Allgemeinen dieselben Charaktere, wie jene der epitheloiden Elemente, uur sind sie meistens etwas kleiner als diese und sehr häufig hyperchromatisch (Fig. 18, 19, 21). Oft haben die Zellkörper der Riesenzellen feine, verzweigte Ausläufer (Fig. 18); ihr Inneres zeigt ausserordentlich hänfig einen wabigen Bau (Fig. 21), häufig auch scharf abgegrenzte Vacuolen; in den Maschenräumen der Waben liegt theils homogene (flüssige?) Masse, theils finden sich daselbst gröbere oder feinere Körner; in den äusseren Theilen solcher Zellen ist häufig eine deutlicher körnige Plasmamasse vorhanden, die keine Wabenstruktur erkennen lässt. Liegt, was nicht selten der Fall ist, nach aussen von der letztgenannten Zone noch eine weitere, hellere, wiederum mit wabigem Bau (Fig. 19), so resultirt hieraus eine dreifache Schichtung des Zellkörpers, welche mit der von Heidenhain für Knochenmarks- 
riesenzellen beschriebenen eine gewisse Analogie zeigt. Endlich kommen schon in ganz jungen Tuberkeln typische, mit polymorphen Kernen versehene Leukocyten vor, welche in späteren Stadien noch an Zahl zunehmen.

Der zweite Punkt, den wir vorausschicken möchten, betrifft das vielfach erörterte Reticulum des Tuberkels, überhaupt dessen $Z$ wischensubstanz.

Die Fixirung der Präparate mit der Hermann'schen Flüssigkeit und nachfolgender Holzessigbehandlung, sowie die Färbung in Sublimat fixirter Präparate mit Ehrlich'scher Triacidlösung (nach Heidenhain) ergeben im Tuberkel eine reichliche Menge grösstentheils faserig aussehender Zwischenmasse, welche aber bei genanerer Untersuchung sich als aus sehr heterogenen Elementen zusammengesetzt erweist und nur zum Theil als wirkliches Reticulum aufgefasst werden darf (Fig. 7). Zunächst zeigen sich am Rande der Knötchen, aber auch in deren inneren Theilen, einzelne, mehr bündelförmig liegende Bindegewebsfasern (Fig. 7 bei a) mit länglichen Kernen; in der Peripherie der Knötchen sind sie oft concentrisch zam Tuberkel angeordnet. Solche Fasern gehen ohne scharfe Grenze in die Umgebung desselben über. Auch nach innen zu strahlen sie in feivere Züge aus, welch' letztere unter verschiedenen Winkeln von ihnen abgehen; ähnliche, etwas dickere Bindegewebszüge finden sich auch im Innern des Knötchens selbst; hier, wie am Rande, liegen ihnen zahlreiche grössere Zellen an, welche einen länglichen, ziemlich hellen und mit chromatischen Körnchen versehenen Kern erkennen lassen, der manchmal am Rande mehrfach eingekerbt ist (Fig. 17, 24) und von einem ganz homogenen Zellkörper umgeben, wird; letzterer setzt sich in zwei oder mehr Fortsätze fort, welche ihrerseits wieder in ein feineres Netzwerk sich auflösen und in der Umgebung verlieren. Bei Holzessigbehandlung sind diese Zellkörper meist gleichmässig dunkelgrau gefärbt.

Aehnliche Bindegewebszüge finden sich in concentrischen Lagen um Gefässe, welche an der Peripherie des Tuberkels gelegen sind, oder welche von einem unregelmässig gestalteten Tuberkel umwachsen warden; die Bindegewebszüge ent- 
sprechen hier wohl grösstentheils der aufgelockerten äusseren Gefässhaut; ähnliche Lagen von Fasern zeigen sich in Lebertuberkeln in der Umgebung von Gallengängen (Fig. 7 bei b), deren Epithel nicht selten gleichzeitig in Wucherung begriffen ist. Auch die an beiden letztgenannten Orten vorhandenen Bindegewebsmassen strahlen in ein feineres Netzwerk aus, innerhalb dessen theils epitheloide Zellen, theils kleine runde Elemente gelegen sind.

Neben diesen dickeren Gebilden findet sich im Tuberkel ein feineres Netzwerk ron scharf gezeichneten, glatten, oft etwas welligen Fasern, die theils einzeln liegen, theils sich zu etwas dickeren Zügen vereinigen (Fig. 7 c, d). Zwischen ihnen bleiben Maschenräume von ziemlich unregelmässiger Weite und Form, doch so, dass die Anordnung des Netzwerks ziemlich dem des Reticulums entspricht, wie es mit der Chromsilbermethode Oppel's in Milz und Lymphdrüsen nachweisbar ist. Es gelang uns indessen nicht, wit der erwähnten Methode auch in Tuberkeln ein Reticulum darzustellen. In die Maschenräume des Netzwerks sind die Zellen des Tuberkels eingebettet und zwar liegen ihnen die feinen Fasern sehr dicht an, so dass sie vielfach als Contouren derselben erscheinen; wo die Zelle eine spindelige Gestalt hat oder sonst an einer Seite spitz ausläuft, erscheint oft ein ihr anliegendes feines Fäserchen wie ein Ausläufer der Zelle, ein Bild, welches bei anderen Behandlungsund Färbemethoden noch täuschender auftritt. Bei Holzessigbehandlung oder Triacidfärbung konnten wir aber in solchen Fällen fast immer erkennen, dass die Faser an der. Zelle vorbeizog und von einem etwaigen protoplasmatischen Zèllfortsatz unterschieden war $^{1}$ ). Auch sieht man an Flächenbilderin von Zellen

1) Trotzdem können wir der Ansicht Kockel's, dass das Reticulum des Tuberkels vorwiegend ein Gerinnungsprodukt sei, hervorgerufen durch die Fixationsflüssigkeit, nicht völlig beistimmen. Denn einmal konnten wir auch an jungen Tuberkeln, und zwar sowohl bei Holzessigbehandlung, wie auch mit der Ehrlich'schen Triacidlösung, eine feinfasrige Masse nachweisen, welche sich von Gerinnselmassen deutlich unterschied, wenn auch durch diese Methoden nachgewiesen wurde, dass die Fasern durchaus nicht, wie früher von uns angenommen wurde, vorzugsweise Zellauslăufer darstellen. Vor Allem aber spricht für die Existenz eines wirklichen präformirten Reticuluas 
oft ein sich durchflechtendes Netzwerk feiner Fasern über dieselben hinziehen. Am Rande, namentlich noch kleiner Tuberkel sieht man häufig auch Capillaren ein Stück weit in das Knötchen hineinziehen; sofern dieselben der Länge nach im Durchschnitt getroffen sind, zeigen sie einen doppelten Contour mit Endothelkernen; im Innern liegt oft eine homogene Masse; solche Bilder gehen häufig in flache Wandschnitte von Capillaren über; des öfteren sieht man auch Capillaren sich in dünnere, etwas gestreifte Züge fortsetzen, die ziemlich weit in den Tuberkel hineinragen und den Eindruck hervorrufen, dass sie collabirten $\mathrm{Ca}$ pillarschlingen entsprechen (Fig. 7, e).

Damit sind indess die Arten der im Tuberkel vorkommenden Zwisehensubstanzen noch nicht erschöpft; vor Allem ist noch

die in gewissen Fällen (siehe unsere erste Arbeit) constatirte byaline Umwandlung und Verdickung eines fasrigen Netzwerks innerbalb der Tuberkel, worauf wir später noch zurückkommen werden. Unseres Erachtens beweist die van Gieson'sche Reaction, wenn dieselbe an einer hyalin aussehenden Substanz zu Stande kommt, so viel, dass diese Substanz von Bindegewebe herstammt, da ja dieses sich mit dieser Yethode mebr oder minder intensiv roth tingirt, und diese Aufnahmefähigkeit für das Fuchsin auch nach seiner byalinen Umwandlung beibehält. Wenn nun in Tuberkeln unter gewissen Umständen ein dichtes, reticulumartiges Netzwerk sichtbar wird, welches diese Reaction giebt, ohne dass ein Eindringen von. Bindegewebe in den Tuberkel nachweisbar wäre, so muss doch von vornherein im Tuberkel ein solches Netz vorbanden gewesen sein, welches sich hinterher erst verdickt bat. Wenn Kockel ein solches in seinen Fällen nicht ausgeprägt sehen konnte, so Jiegt das wohl daran, dass ihm, ebenso wie uns in der bier bescbriebenen Versuchsreihe, keine jene Unwandlung aufweisenden Tuberkel vorlagen, wie ja solche auch nur unter bestimmten Umständen auftreten. -

Endlich können wir in dem Reticulum keineswegs ein blos durcb die Fixirungsflüssigke it bervorgerufenes arteficielles Produkt sehen, wie aus dem in Folgenden angegebenen und genügend hervorgehobenen, successiven Auftreten dieser $Z$ wischenmasse, der Beziehung derselben zum Schwinden der Kerne und zur käsigen Umwandlung hervorgeht.

[Die Abbanding Kockel's (Beitrag zur Histogenese des miliaren Tuberkels. Dieses Archiv. Bd. 143. S. 574) ist uns erst nach Abschluss unserer Arbeit zu Gesicbt gekommen und konnte daber leider nicht mehr genauer berücksichtigt werden.] 
eine Masse zu erwähnen, auf welche wir unten noch näher einzugehen haben, und welche theils in Form feiner Körnchen oder Fäden, theils in Form dicker, homogener Stränge zwischen den übrigen Elementen hinzieht und besonders im Centrum der Knötchen frühzeitig auftritt (Fig. 7,f). An den Gallengängen nimmt auch eine zwischen den Epithelien derselben gelegene Kittmasse mit Holzessig und Triacidlösung einen äbnlichen Farbenton an, wie die oben beschriebenen Fasern, so dass an einzelnen Stellen die Natur der Zwischensubstanz oft recht schwer zu beurtheilen ist. Auch im Lumen der Gallengänge erkennt man nicht selten ähnlich aussehende, meist jedoch etwas hellere Fäden, die zum Theil wobl Secretmassen entsprechen.

An ganz jungen Tuberkeln der Leber, der Milz, Lymphdrüsen und anderer Organe, an welchen eben die centralen Theile durch eine andere Beschaffenheit, meist dunkle Färbung mit diffus tingirenden Farbstoffen, sowie mit Holzessig hervortritt, sehen wir hauptsächlich folgende Veränderungen: Fibrinabscheidung zwischen den Zellen, die Bildung einer eigenthümlichen anderen, ebenfalls wesentlich $z$ wischen den Zellen gelegenen Masse und endlich Umwandlungen der Zellen selbst.

Von diesen Veränderungen tritt im ersten Stadium die an zweiter Stelle genannte am meisten hervor. Wir finden an den veränderten Stellen ein eigenthümliches Netzwerk einer bereits oben erwähnten Substanz, das sich auf's engste an die Zellcontouren anschmiegt und an einigen Stellen eine grosse Aehnlichkeit mit dem Reticulum aufweist, andererseits aber sich wesentlich von demselben unterscheidet (Fig. 7). Zum 'Theil finden sich hier feine Fasern, die aber meistens nicht so scharf gezeichnet sind, wie-die Reticulumfasern, sondern mehr unregelmässig und unscharf begrenzt erscheinen, öfter auch wie aus Körnchen bestehend aussehen und nicht selten mehrfach unterbrochen sind; zum anderen Theil sind die Balken dicker und gröber und von unregelmässig knorriger, ästiger Gestalt. Auch da wo die Fäden des Netzwerks sehr fein sind, zeigen sich die Knotenpunkte desselben etwas verdickt, und zwar in der Art, dass die Ecken der Maschenräume von einer; nach innen concav begrenzten Verdickung der Balken abgerundet 
werden. Vielfach sind die Maschenräume bedeutend enger als die des Reticulums, namentlich auch sehr eng im Verhältniss zu den sie bildenden Fasern selbst und vielfach bleiben zwischen den letzteren nur kleine vacuolenartige Hohlräume übrig. Endlich sieht man nicht selten auch scharf gezeichnete, ganz glatte Fasern, die vielleicht dem Reticulum angehören, aber mit körnigen Partikeln oder unregelmässigen, varicösen Anschwellungen besetzt sind und den Eindruck machen, als habe sich eine körnige Masse am Reticulum niedergeschlagen. Dem gegenüber findet man auch an verschiedenen Stellen ganz dicke und plumpe, balkenförmige bis tropfenförmige Gebilde von sonst homogener Beschaffenheit.

Dieses Aussehen zeigen die jungen Tuberkel an Präparaten nach Sublimatfixation und Triacidfärbung. Die eben beschriebene Zwischenmasse zeigt bei letzterer Färbung meistens einen auffallenden, etwas mehr violetten Farbenton. Bei Färbung mit van Gieson'scher Mischung tritt die Substanz wenig hervor; sie färbt sich dabei immer gelb, nie roth; auch Eosin nimmt sie ziemlich wenig an.

Ein besonderes Interesse beansprucht natürlich das Verbalten derselben gegenüber der Weigert'schen Fibrinfärbung. Dass mit letzterer in. Tuberkeln überhaupt vielfach Fibrin nachweisbar ist, wurde in letzter Zeit in mehreren Arbeiten hervorgehoben, so von Ortner, Falk, Schmaus u. A.; übrigeus hat schon Baumgarten die Anwesenheit von Fibrin in Tuberkeln, allerdings noch ohne die Weigert'sche Fibrinfärbung, erwähnt. In unseren Fällen konnten wir ebenfalls mit Hülfe dieser Methode Fibrin in den Knötchen nachweisen, aber fast immer nur in relativ geringer Menge. Ziemlich constant fanden sich einige blaugefärbte Fasern um die grösseren Riesenzellen, und zwar oft in der Art, dass einzelne feine Fibrinfäden oder Bündel von solchen einen scharfen Contour der Riesenzellen nach einer oder mehreren Seiten hin herstellten und von hier aus über grössere Strecken; oft durch den ganzen Tuberkel ausstrahlten. Weitaus die Hauptmasse der vorhandenen, oben erwähnten Zwischensubstanz wurde jedoch bei der. Anilinölbehandlung mehr oder minder vollkommen entfärbt oder behielt nur einen blassblauen Farbenton, wie auch andere faserige Gebilde, namentlich elastische 
Fasern ihn öfters annehmen. Wir wollen sie daher vorläufig als Fibrinoid vom Fibrin unterscheiden und nochmal hervorheben, dass sie an verschiedenen Stellen und je nach ihrer Menge bald mehr körnig oder feinfaserig, bald dickbalkig oder hyalin aussehen kann. Nachdem nun die Möglichkeit, dass faseriges Fibrin durch eine Art von Umprägung sich direct in hyaline Masse umwandeln kann, wohl von allen Seiten zugegeben wird, läge auch hier die Annahme nahe, dass unser Fibrinoid auf diesem Wege sich gebildet habe. In diesem Sinne könnte man es deuten, dass dickere, hyaline Balken manchmal einen leicht blau gefärbten Saum nachweisen lassen. Auch liegen ihnen öfters intensiv blaugefärbte Fadennetze oder Körner seitlich an. Da wir aber Fibrin fast immer blos in spärlicher Menge nachweisen konnten, während Fibrinoid schon von Anfang an, d. b. in ganz jungen Tuberkeln reichlich vorhanden ist, so kann man dennoch kaum annehmen, dass das Letztere aus faserigem Fibrin entstanden ist. Eher könnte man glauben, dass die fibrinoiden Balken durch seitlich angelagertes, sich zu Hyalin umprägendes Fibrin noch weiter verdickt würden. Doch finden sich eben an den hyalinen Balken auch körnige und körnigfädige Massen anliegend, welche die Fibrinreaction ni cht geben.

Es soll weiter vorläufig nur erwähnt werden, dass dem Fibrinoid ähnliche Massen sich häufig auch im Lumen und in der Umgebung von Gefässen fanden, die in Tuberkeln erhalten geblieben waren, oder sich in dessen Nähe befanden. Im Lumen von Gefässen schloss die fibrinoide Masse hie und da Leukocyten ein.

Wir verschieben nun die weitere Erörterung über die mögliche Herkunft des Fibrinoids und wenden uns zunächst zu den Veränderungen, die wir an den Zellen des verkäsenden Tuberkels wahrnehmen konnten.

Es muss hier ein Befund vorausgeschickt werden, welchen wir schon in ganz jungen Knötchen sehr häufig constatiren konnten. Im Centrum derselben fanden sich zwei oder mehr, im letzteren Falle gruppenweise zusammenliegende Zellen, deren Kerne nicht mehr färbbar waren. Doch waren dieselben noch mehrfach an ihren Contouren und ihrer sonstigen Struktur er- 
kennbar, hatten also nur die Fähigkeit der Farbstoffaufnahme verloren. In anderen solcher Zellen waren Kerne überhaupt nicht mehr nachweisbar; dann zeigte sich die ganze Zelle dunkel, stark körnig, bei Holzessigbehandlung mit schwarzgrauen Körnern versehen. Manchmal zeigt sich statt mehrerer Zellen eine grössere, unregelmässig gestaltete kernlose Masse, die ebenfalls von körniger Beschaffenheit ist, ausserdem aber mehr oder minder reichliche faserige Gebilde erkennen lässt; letztere sind entweder feinfaserig, manchmal auch netzförmig angeordnet, oder gröber, unregelmässig und von scholligem, balkigem Aussehen; theils durchziehen sie die körnigen Massen, theils scheinen sie denselben aufzuliegen. Es dürfte sich bei diesen Ablagerungen wohl um solche des oben erwähnten Fibrinoids handeln, während die kernlosen, körnigen Massen wenigstens zum Theil vielleicht Abschnitten von Riesenzellen entsprechen. Ferner kommen in derartigen Partien kleine, rundliche, theilweise mit Safranin färbbare, theilweise bei Holzessigbehandlung intensiv dunkelgraue Partikel vor, welche wohl Zerfallsprodukten weisser Blutkörperchen entsprechen, wie wir sie unten noch einmal genauer anführen müssen.

Wenden wir uns nun mehr zu den im Fibrinoid eingeschlossenen Zellen, so ist noch vorauszuschicken, dass die Ausbeute an positiven Befunden an ihnen, sowie auch an ihren Kernen eine sehr geringe war; namentlich zeigen ihre Veränderungen einen sehr geringen Formenreichthum gegenüber denen, welche man bei einfacher anämischer Nekrose von Epithelien erkennen kann.

Sehr häufig ist die Grenze zwischen den fibrinoidhaltigen und den umgebenden, noch unveränderten Theilen des Tuberkels eine ganz scharfe, an den Stellen, wo erstere beginnen, zeigen sich die Zellen als solche fast vollkommen verschwunden. Man findet hier blos mehr ein compactes, von Spalten durchsetztes Balkenwerk, das nur an lockeren Stellen eine reticulumartige Anordnung zeigt, während an den dichteren Partien die Balken sich vielfach berühren, und mehrfach auch mit einander verschmolzen sind. Nur an verhältnissmässig wenigen Stellen zeigt sich die Grenze des Fibrinoids gegen die äussere Zone weniger scharf und es treten dann, in der Richtung von aussen 
nach innen, zuerst einzelne feine Fäden auf, welche von unregelmässigen, körnigen oder bröckligen Partikeln durchsetzt werden und hiedurch sich von Reticulumfasern unterscheiden. Zwischen ibnen liegen zunächst vereinzelte schollige Massen, von rundlicher, eckiger oder länglicher, manchmal verzweigter Gestalt, welche nach inven zu zahlreicher werden und za compacteren Massen fibrinoider Substanz sich zusammen schliessen, die schliesslich dann ganz homogen und höchstens von sehr feinen Spalträumen durchsetzt sind: In lockeren Stellen erscheinen die feineren, fadenartigen Gebilde mehrfach als Fortsätze mehr rundlicher oder eckiger Partikel. In den centralsten Theilen etwas älterer Knötchen, wo also die Degeneration schon seit längerer Zeit eingesetzt hat, findet man statt des balkig-hyalinen Fibrinoids und der Zellen nur mehr eine feinkörnige, dichte Detritusmasse, welche peripheriewärts in die eben beschriebenen, etwas lockereren und mehr grobscholligen Partikel übergehen.

Nur an wenigen Stellen sind überhaupt noch Zellen erkennbar, und hier mit deutlichen Uebergängen in kernlose Massen. Die meisten sind homogen und schollig umgewandelt, oft zeigen sie ausserdem noch in wechselnder Menge eingelagerte Vacuolen; manche weisen einen ausgesprochenen wabigen Bau auf. Oft sieht man auch den Kern vom Zellplasma durch einen hellen Hof oder eine Reihe dicht liegender kleiner Vacuolen getrennt und ersteren selbst von kleinen Hohlräumen durchsetzt. Manche Zellkörper endlich zeigen eine Umwandlung in körnige oder körnig-netzige Massen, und endlich erscheinen wieder andere so unregelmässig gestaltet, dass man eine Zerklüftung derselben in eine Anzahl von Theilstücken annehmen muss. Alle diese Umwandlungsprodukte von Zellen zeigen in ihrem tinctoriellen Verhalten eine völlige Uebereinstimmung mit dem Fibrinoid; sie werden mit Eosin röthlich, durch Fuchsin (Triacidlösung) intensivroth (etwas violettroth), durch Holzessig dunkelgrau.

Die Kerne der so zu Grunde gehenden Zellen schwinden sehr frühzeitig, aber die Formen, unter denen der Kernuntergang erfolgt, sind ziemlich spärliche. Oefters sieht man mitten in balkigen Massen, und zwar in den Balken selbst, nicht nur in den Maschenräumen gelegen, ganz blass gefärbte, undeutliche Kerne, um welche herum ein Zellleib nicht mehr differenzirbar 
ist; öfters sind sie durch einen Hof von der umgebenden Masse abgetrennt, ähnlich wie er sich auch zwischen Kern und homogen umgewandeltem Zellkörper öfter findet. Andere Kerne zeigen Kerawandhyperchromatosen und Kerawanddegeneration, manche davon genau dem von Flemming als Chromatolyse bezeichneten Typus entsprechend. Sprossungsfiguren sind höchst selten und nie in guter Ausbildung vorhanden; häufig findet man dagegen ausgeprägte Formen der Pyknose verschiedener Art. Neben homogen aussehenden, sich mit Safranin dunkel färbenden, compacten, rundlichen Kernen liegen auch solche mit geringer oder schon aufgehobener Färbbarkeit, die aber durch den Holzessig einen anffallend tiefgrauen Farbenton annehmen (Fig. 8, 9, 11). Im Inneren, wie am Rande solcher Kerne finden sich - ebenso wie auch im zugehörigen Zellleib - häufig kleine Hohlräume, bezw. Einbuchtungen (Fig. 10). Auffallend ist, dass an manchen sonst noch ziemlich gut erhaltenen Kernen eine auffällige Verdickung der chromatischen Kernmembran hervortritt (Fig. 12).

Weiterhin finden sich Bläschenformen, bei denen der Kern in eine Anzahl rundlicher, chromatischer, im optischen Durchschnitt einen Ring darstellender Gebilde zertheilt erscheint; desgleichen ähnlich gebaute Ma ul be erfor men, wo kleine Chromatinbläschen an einander stossen und $\mathrm{zu}$ Häufchen gruppirt sind, endlich Gitterformen und Wabenformen, bei denen der Kern in eine Anzahl polygonaler bis rundlicher, heller Räume getheilt ist, die durch straugartige Chromatinstreifen getrennt sind (Fig.13). Von diesen Kernen zeigen einige die schon früher beschriebene Auffaserung am Rande (Fig. 14), indem an einzelnen der peripherisch gelegenen kleinen Hohlräume die äussere Begrenzung fehlt, so dass die betreffende Wabe nach aussen offen ist. Zum Schluss sei bemerkt, dass sonst wenig veränderte Kerne mehrfach sehr klein, zackig und wie geschrumpft aussehen. Alle diese Degenerationsformen wurden von uns schon früher in der Abhandlung über Karyorrbexis näher beschrieben und daher im Vorhergehenden nur kurz erwähnt.

Durch dieselben wird die Form und Struktur der Kerne so hochgradig verändert, dass meist nicht mehr entschieden werden kann, welchem der Eingangs angeführten Zelltypen - 
grössere epitheloide oder kleinere, runde Kellen - der betreffende Kern angehört hat. Die im Stadium der Fibrinoidbildung schon reichlich vorhandenen, mit polymorphen Kernen versebenen Leukocyten sind an der charakteristischen Gesammtform ihrer Kerne meist lange Zeit hindurch erkennbar. Aber gerade an ibnen zeigen sich in sehr reichlicher Zahl Formen der Kernwandhyperchromatose und Kernwanddegeneration oder dicke Gerüstfiguren, Bildung sichelförmiger bis ringförmiger Chromatinkörper am Rande und Trennung der Chromatinkörnchen zu isolirten Gebilden (Fig. 33-38). Ferner finden sich bläschenförmige und maulbeerförmige Kerne, Verdichtung des Kernes mit Anfangs gleichmässiger Erhöhung, später Herabsetzung der Färbbarkeit, endlich dunkelgraue (Holzessig) compacte Kerne mit oder ohne Chromatinreste. Sehr häufig finden sich endlich die schon von anderen Autoren (Marchand, Arnold, Heidenbain) beschriebenen Formen, die man vielleicht am besten als Hyperfragmentirung bezeichnet, bei welcher die Zellfragmente immer zahlreicher werden, und schliesslich der Prozess zu einer Ansammlung kleinster Chromatinpartikel führt.

Der Umstand, dass an den Kernen der eigentlichen Tuberkelzellen, d. h. den epitheloiden Elementen, Chromatinumlagerungen and Formen der Karyorrhexis überhaupt nur in spärlicher Menge uachweisbar sind, lässt wohl darauf schliessen, dass beim Uebergang ihrer Kerne dem einfachen Schwinden des Chromatins (einer Auslaugung desselben) eine grosse Rolle zukommt, und dass weiterhin an den chromatinlos gewordenen Kernen noch Veränderungen stattfinden, welche wir als metachromatische bezeichnet haben; doch sind diese Veränderungen gerade an den Tuberkeln schwer nachzuweisen, weil die Zellkörper sehr bald nicht mehr von der fibrinoiden Masse za unterscheiden sind. Nachdem wir andererseits an den eingewanderten Leukocyten mit Umordnung des Chromatins einhergehende Degenerationen in reichlicher Zahl vorfanden, und Leukocyten auch in späterer Zeit in grosser Menge einwandern, so ist wohl der Schluss gerechtfertigt, dass die meisten der in späteren Stadien der Verkäsung noch nachweisbaren Chromatinbröckel Zerfallsprodukten von Leukocytenkernen entsprechen. 
Wir konnten also den Vorgang der Verkäsung bis zum Auftreten einer, in ihren ersten Anfängen fädig-netzförmig angeordneten Substanz zurückverfolgen; welche im weiteren Verlauf des Prozesses eine Zerklüftung zu kleineren Schollen und Bröckeln erfährt, und schliesslich in der Bildung eines Detritus aufgeht. In frischen Stadien aber steht die Masse ihrem Aussehen nach der Gruppe der hyaline a Substanzen nahe und es wäre nun zunächst $z u$ entscheiden, wie ihr Auftreten sich zu der schon mehrfach erwähnten hyalinen Umwandlung der Tuberkel verhält. Weiterhin ist das Verhalten letzterer zu einer, unter verschiedenen Namen beschriebenen Veränderung der Knötchen $z \mathfrak{u}$ constatiren, welche im Wesentlichen auf dem Auftreten eines derben, glasigen, sklerosirenden Bindegewebes um dieselben und in ihrem Inneren beruht.

Hierher gehört zunächst die von Schüppel beschriebene Einkapselung der Tuberkel: dieselbe geht von dem umgebenden Bindegewebe aus, oft ganze Gruppen von Tuberkela zusammen umfassend und an ihr betheiligt sich, obwohl nach Schüppel's Ansicht nur in untergeordnetem Maasse, auch das Tuberkelreticulum. Das dabei gebildete fibröse Gewebe zeigt eine homogene, glasige Beschaffenheit, welche auch in's Innere des Tuberkels eindringt, und in manchen Fällen vielleicht den ganzen Tuberkel betreffen kann. Schüppel dentet die Bildung dieses Gewebes als reactive Erscheinung, mit welcher die Umgebung des Tuberkels auf den von ihm gesetzten Reiz antwortet. Es entsteht so nach Schüppel der ächte encystirte (eingekapselte) Tuberkel. Makroskopisch erscheint derselbe als glasiges, helles Knötchen (a. a. 0. S. 109), an dem man ein trübes, opakes (verkästes) Centrum erkennt. Neben der Einkapselung der Tuberkel erwähnt Schüppel in tuberculösen Organen noch die Bildung von Zügen glasigen Bindegewebes, welche unabhängig von Tuberkeln auftreten.

Aehnliche Befunde finden sich an Tuberkeln beschrieben von Wieger und Cornil, welche, wie Schüppel, darauf hinweisen, dass man es hier jedenfalls nicht mit Hyalin (d. h. der von Wieger beschriebenen Form desselben) zu thun habe, vielmehr mit einer Umwandlung des Bindegewebes des Reticulums zu einem eigenthümlichen, sklerotischen, zellarmen Gewebe, 
welche ganz einer eigentlichen Bildung von Narbengewebe entspreche.

Dem gegenüber bezeichneten Uschinsky und Schmaus (Ueber den Verlauf der Impftuberculose unter der Einwirkung von Alkalialbuminat. Dieses Archiv. Bd. 136. S. 264) eine im Wesentlichen mit der erwähnten übereinstimmende Veränderung in den Tuberkeln als Hyalinbildung im Sinne vou Ernst (Dieses Archiv. Bd. 130. S. $279 \mathrm{ff}$.), da die Substanz dessen Farbenreaction mit der van Gieson'schen Mischung gab. Im Gegensatz zu den Angaben Schüppel's fanden wir nicht blos das peripherische, den Tuberkel umgebende Bindegewebe, sondern auch das Reticulum des Tuberkels selbst wesentlich an der Bildung der fraglichen Substanz betheiligt, wenn auch der Prozess im Ganzen und Grossen, entsprechend den Angaben Sch üppel's, in den peripherischen Bezirken des Tuberkels und seiner Umgebung beginnt und von da nach dem Centrum des Knötchens fortschreitet. Es handelt sich nach unserer Auffassung um Einlagerung der hyalinen Substanz in das Bindegewebe und das sich verdickende Reticulum, zum Theil auch in die Zellen des Tuberkels.

Wir hatten also zunächst die in der letztgenannten Abhandlung als Hyalin bezeichnete Substanz in ihrem Verhältniss zu der hier von uns vorläufig als Fibrinoid benannten zu untersuchen. Es war uns in dieser Beziehung besonders lehrreich der Vergleich unserer Präparate mit den schon früher veröffentlichten Fïllen von Impftuberculose, in welchen - an der gleichen Thierart, an Meerschweinchen, und ebenso an Kaninchen, - sich eine von aussen nach innen fortschreitende Umwandlung der Knötchen neben einer centralen Verkäsung derselben vorfand. Dabei ergab sich nun, dass von dem damals beschriebenen, und als hyalin bezeichneten Stoff sich in unseren neueren Versuchen so gut wie nichts nachweisen liess, dass also jenes Hyalin nicht mit unserem Fibrinoid identisch ist und auch nicht eine Vorstufe der Verkäsung darstellt. Die Gründe, welche uns zu dieser Anschauung geleitet haben, sind die folgenden:

1) Zunächst lässt sich wenigstens mit einer Farbmischung ein Unterschied in der Reaction erkennen, welcher durch seine Constanz und im Verein mit den anderen histologischen Merk- 
malen wohl auf einen durchgreifenden Unterschied beider Substanzen schliessen lässt. In Tuberkeln der letzten, in vorliegender Arbeit beschriebenen Versuchsreihe zeigt die fibrinoide Substanz, wie erwähnt, mit Carmin und Eosin eine röthliche, mit Triacidlösung eine intensiv rothe, mit der van Gieson'schen Mischung unter allen Umständen eine gelbe, nie eine rothe Farbe, und zwar gelten diese Farbenreactionen sowohl für die noch homogenen, grobscholligen Massen, wie auch für den körnigen Detritus. Dagegen zeigten Schnitte von der früheren Versuchsreihe (Schmaus und Uschinsky), mit unseren jetzigen Farblösungen tingirt, Folgendes: Die früher als hyalin bezeichnete Substanz färbt sich intensiv roth sowohl mit der Triacidlösung wie auch mit Carmin und der van Gieson'schen Mischung; wo dagegen ein körniger Zerfall vorhanden war, färbten auch in jenen Präparaten die Massen sich mit van Gieson gelb und niemals roth. Während also die Triacidlösung keinen Farbenunterschied zwischen dem Fibrinoid und jenem Hyalin ergiebt, zeigt sich ein solcher mit der van Gieson'schen Farblösung, indem dieselbe dieses gelb, jenes ebenso constant roth färbt.

Wenn wir nun auch vollkommen der Ansicht von Lubarsch beistimmen, dass die Rothfärbung des Hyalins mit der van Gieson'schen Farblösung nicht dem Hyalin an sich eigen sei, sondern von Beimischungen herrühre, welche aus der Substanz stammen, aus der das Hyalin sich gebildet hat, so scheint uns doch in unserem Falle die Farbenreaction gerade deswegen von Bedeutung, weil sie uns nachweist, dass das Hyalin und das Fibrinoid aus verschiedenen Substanzen herstammen.

2) Auch im übrigen histologischen Verbalten zeigen sich erhebliche Unterschiede: Das Fibrinoid, die sich gelb färbende Substanz ( $v$ an Gieson), tritt in den ersten Anfängen in den Spalten zwischen den Zellen in einer feinkörnigen bis netzförmigen Anordnung auf; sehr bald verschwinden auch die Zellkörper und sind als solche nicht mehr zu erkennen; dadurch wird die Masse compact und zeigt höchstens noch einzelne Spalten, zwischen denen Kerne eingeschlossen sind. Am Rand der Fibrinoidbildung hört die Struktur des Tuberkels ziemlich plötzlich auf; Zellen und Reticulum sind nicht mehr zu unterscheiden und letzteres verschwindet an den Stellen, wo die genannte Masse auftritt. Nir- 
gends konnten wir einen Uebergang des Reticulums in Fibrinoid constatiren; nur an ein paar Stêllen, welche wir unten noch einmal erwähnen müssen, ragten einzelne Reticulumbalken eine kurze Strecke weit in die fibrinoide Masse hinein. Demgegenüber zeigt die sich roth färbende Substanz (das Hyalin der früheren Versuchsreibe) eine deutliche Beziehung zum Retjculum, überhaupt zu den faserigen Elementen des Tuberkels und seiner nächsten Umgebung. Am Rande des Knötchens sehen wir vorzugsweise circulär verlaufende, theils feinere, theils dickere, theils schon ganz homogene und zu breiteren Bändern sich an einander legende Faserbündel und vielfach kann man Uebergänge der faserigen Massen in homogene Bänder finden. Gegen das Innere des Knötchens zu nimmt die rothe Substanz in ausgesprochener Weise die Anordnung des Reticulums an und durchzieht als zusammenhängendes, vielfach anastomosirendes Maschenwerk den Raum zwischen den noch wenig veränderten Zellen. Die Balken dieses Maschenwerks sind von verschiedener Dicke, sie zeigen allmäbljche Anschwellungen und Abschwellungen, nirgends aber jenen zerklüfteten, grobschollig-faserigen Charakter, wie ihn das Fibrinoid schon in frühen Stadien erkennen lässt. Die eingelagerten $Z e l l e n$ zeigen auch dann, wenn der Tuberkel schon in grosser Ausdehnung von dem hyalinen Netzwerk durchzogen ist, keinerlei schollige Zerklüftung und weisen wenigstens lange Zeit hindurch wohl erkennbare Kerne auf. Nirgends findet man die unregelmässige, dichte Zusammenlagerung wie beim Fibrinoid, das alle Spalträume zwischen den Zellen ausfüllt.

In Lymphdrüsen und Milz, wo die Tuberkel vielfach in sonst noch wenig verändertem Gewebe liegen, zeigt auch das mit ihnen zusammenhängende Reticulum dieser Organe nicht selten eine Verdickung seiner Fasern und Uebergänge in die hyalinen Züge des Randes der Knötchen.

3) An den oben bereits erwähnten, spärlich vorkommenden Stellen, wo hyaline Reticulumbalken in die körnige Detritusmassen hineinreichen, zeigen die ersteren von der Stelle $a b$, wo sie von körniger Masse umgeben sind, eine Aenderung ihrer Färbbarkeit, indem sie von da ab auch ibrerseits das Säurefuchsin abweisen und die Pikrinsäure aufnehmen.

4) Die hyaline Umwandlung der Tuberkel beginnt 
an deren Peripherie und schreitet von da aus nach dem Centrum derselbenfort; die Verkäsung und die Fibrinoidbildung beginnen fast immer in den centralsten Theilen, niemals am Rande der Knötchen und dehnen sich in centrifugaler Richtung aus. Diese regelmässig nachweisbare Verschiedenheit im Ausgangspunkt lässt wohl an sich schon

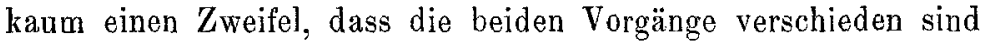
und die hyaline Umwandlung nicht etwa eine Vorstufe der Verkäsung ist, sondern selbständig neben derselben auftreten kann. Wohl aber kann gelegentlich dieses Hyalin noch nachträglich einer Verkäsung anheimfallen und wir glauben jene oben erwähnten Stellen in diesem Sinne deuten zu sollen, wo die verdickten Reticulumbalken eine Aenderung der Farbeureaction zeigten. - Endlich spricht auch der Umstand, dass die hyaline Umwandlung sich nicht auf den. Tuberkel beschränkt, sondern auch und zwar in sehr hohem Grade seine Umgebung betrifft, entschieden für die Selbständigkeit dieses Prozesses gegenüber der Verkäsung.

5) Es scheint auch, dass die fibrös-hyaline Umwandlung $7 u$ einer Veränderung führt, welche mehr als eine dauernde, ja. sogar als eine Art von Heilungsvorgang angesehen werden darf, während die Fibrinoidbildung vorzugsweise als Vorstadium eines bald sich einstellenden, körnigen Zerfalls zu betrachten sein wird. Auch in glasigen, derben, sog. obsoleten Tuberkeln menschlicher Lungen, namentlich in cirrhotischen Partien der Iungenspitze, fanden wir vielfach das oben erwähnte Hyalin; die Anordnung desselben, die Färbbarkeit mit Säurefuchsin und den allmählichen Uebergang in die fibröse Umgebung, so dass wir auch diese Abheilung der Tuberkel wesentlich auf fibröshyaline Umwandlung derselben beziehen möchten.

Was wir in der früheren Arbeit als "Hyalin" im Sinne Ernst's bezeichnet haben, muss also jedenfalls von der fibrinoiden Substanz als etwas ganz Andersartiges abgetrennt werden. Dagegen scheint es uns - entgegen der Ansicht Schüppel's, Cornil's und Wieger's berechtigt, auch diese bindegewebige, "skierotische" Masse als Hyalin zu bezeichnen und zwar mit Rücksicht auf ihr makroskopisches und mikroskopisches Verhalten das dem des hyalinen, sklerosirenden Bindegewebes entspricht, 
wie es auch an Gefässen u. s. w. von Alters her so bezeichnet wird. Wir können es wohl mit Recht als conjunctivales Hyalin bezeichnen.

Ein Zweifel über die Berechtigung dieser Terminologie könnte in zweierlei Richtung auftauchen. Einmal könnte man das hyaline Aussehen der fraglichen Masse ausschliesslich auf dichte Zusammenlagerung von Bindegewebsfasern zurückführen, andererseits auch versucht sein, die ganze Umwandlung des Tuberkels blos auf eine, das Knötchen von aussen her umhüllende und mehr oder minder weit durchdringende fibröse Umwandlung aufzufassen und dieselbe im Sinne Schüppel's als reactive Bindegewebswucherung zu bezeichnen.

Was den ersten Punkt betrifft, so glauben wir, dass selbst dann noch eine Berechtigung bestände, die Umwandlung als hyalin zu bezeichnen, wenn es sich blos um eine ganz dichte Zusammenlagerung der Fasern und Verschmelzung derselben handeln würde. Es scheint aber, dass die Fasern, bevor sie sich zusammenlegen, eine Verdickung erleiden, dass also eine, wenn auch geringfügige Massenzunahme an ihnen stattfindet und eine Einlagerung einer Substanz in sie stattfindet. Dafür spricht auch die Art und Weise wie die hyaline Degeneration in anderen Fällen, z. B. an Capillaren, stattfindet, wo man doch eine Zusammenlagerung verschiedener Schichten nicht annehmen kann, and das Gleiche ist in unseren Versuchen mit dem Tuberkelreticulum der Fall, wo ebenfalls zunächst eine Verdickung, nicht eine Zusammenlagerung seiner Fasern nachweisbar ist; denn die Anordnung der Reticulumbalken erscheint trotz ihrer hyalinen Verdickung lange Zeit hindurch unverändert, was wohl nicht der Fall sein könnte, wenn die Verdickung derselben nur durch Aneinanderlegen einzelner Fasern zu Stande käme; auch müssten im letzteren Falle die Zellen zwischen den sich an einander legenden Fasern doch in grösserer Zahl schwinden. Allerdings besitzen wir noch keine sichere Methode, das Reticulum des Tuberkels mit genügender Schärfe darzustellen und es wäre nicht ausgeschlossen, dass eine Methode, wie die von 0 ppel und von Mall für das normale Reticulum angewendeten, auch in Tuberkeln eine viel grössere Zahl feiner Fasern darstellen könnte, als wir bisher erkennen können, und dann wäre es wohl auch möglich, 
dass die uns hyalin erscheinenden dickeren Balken des Reticalums bereits durch Zusammenlagerung feinster Fasern entständen; bis jetzt aber haben wir für eine derartige Annahme noch keinerlei positive Anhaltspunkte.

Was den zweiten Punkt, nehmlich die Annahme betrifft, dass die Umwandlung des Knötchens wesentlich von seiner Umgebung ausgehe (Schüppel), so spricht dagegen nicht blos das frühzeitige Auftreten der hyalinen Substanz am Reticulum, sondern vor Allem der Umstand, dass letzteres dabei seine Anordnung behält. Würde von aussen her wucherndes, später sklerosirendes Bindegewebe in das Knötchen eindringen, so müsste die reticuläre Struktur des letzteren mehr oder minder schwinden, wenigstens ibre Form ändern. Ferner findet man wohl überall da, wo eine derartige bindegewebige Organisation vor sich geht, auch eine Neubildung von Gefässen, wie wir sie ja in analogen Fällen bei Gummen nachweisen können; auch für Tuberkel ist in letzter Zeit von Richter eine derartige Vascularisation und Organisation (nach Einwirkung von Zimmtsäure) nachgewiesen worden. Da nun in unseren Fällen von einer Gefässneubildung nichts zu erkennen. war, so wird es sich auch wohl nicht um eine bindegewebige Organisation im gewöhnlichen Sinne handeln.

Andererseits ist, wenn wir za der von uns vorläufig als fibrinoid bezeichneten Substanz zurückkehren, nicht zu leugnen, dass man auch diese mit eben so viel Recht in die Gruppe der hyalinen Substanzen zählen kann; ja sie scheint uns gerade dem nahe zu stehen, was von den meisten Autoren, namentlich von Vallat, als Hyalin im Taberkel beschrieben worden ist. Es trifft auch für unser Fibrinoid die Zusammensetzung aus einer homogenen Grundsubstanz und einem Kanalsystem zu, ebenso auch die Art seines Fortschreitens von innen nach aussen. Dagegen besteht allerdings eine Thatsache, welche begründete Zweifel an der völligen Identität desselben mit dem Vallat'schen Hyalin erwecken muss. Während wir Fibrinoid in allen Tuberkeln nachweisen konnten, die überhaupt ein kernloses Centrum zeigten, constatirte Vallat sein Hyalin in Tuberkeln mancher Organe nur als einen häufigen, in anderen Organen sogar als einen ziemlich seltenen Befund; häufig fand er es in Lymphdrüsen und Milz; dagegen in der Leber unter 
20 Fällen $5 \mathrm{mal}$, in der Lunge $1 \mathrm{mal}$, auch in der Niere nur selten. Es scheint uns dennoch sehr fraglich, ob wir die gleiche Substanz wie Vallat vor uns hatten. Ueber die Genese seines kanalisirten Fibrins spricht sich Vallat nicht näher aus; insbesondere lässt er es unentschieden, ob man dasselbe mit Langhans dem Fibrin oder mit v. Recklinghausen dem Hyalin zurechnen müsse. Er hält übrigens die Entstehung der einzelnen Schollen aus epitheloiden Zellen für möglich und will sie sogar in Tuberkeln der Lymphdrïsen direct beobachtet haben. In einem anderen Falle nimmt $V$ allat eine Entstehung seines kanalisirten Fibrins durch exsudative Prozesse an. Es handelte sich um einen Fall von käsiger Pneumonie, wo weder Riesenzellen, noch Tuberkel nachweisbar waren, wobei eine netzförmige hyaline Substanz in den Alveolen auftrat, in deren Maschen homogene Bröckel eingelagert waren, die wie Zellen aussahen, aber keine Kerne besassen. Die Alveolarwände waren in der gleichen Weise verändert; auch die Blutgefässe waren degenerirt and ihre Umgebung zeigte stellenweise kanalisirtes Fibrin.

Was die Bildung der Kanäle anlangt, so stellt Vallat verschiedene Möglichkeiten auf; Zusammenfliessen der Zellen und secundäre Entstehung der Kanäle von den Stellen der eingeschlossenen Kerne her; oder die Kanäle verdanken ihre Entstehung einem Strom von Ernährungsflüssigkeit, oder einer Einwanderung von farblosen Blutkörperchen. Da die hyaline Sub$\operatorname{stanz}$ an ihrer Peripherie constant aus kleineren Schollen zusammengesetzt ist, so muss nothwendig beim Entstehen des kanalisirten Fibrins ein Zusammenfluss kleiner Schollen stattfinden. Endlich könnte man nach Vallat unter der Annahme, dass die letzteren sich zu einem Netzwerk vereinigen, einfach durch Anschwellen der Balken desselben die Bildung der Substanz erklären: die Kanäle würden weiter aus einander rücken und die grösseren Distanzen der Kerne im centralen Theile würden sich auch so erklären. Oder es könnte ein Wachsthum durch Intussusception stattfinden, wie es Langhans für das kanalisirte Fibrin der Placenta annimmt. Jedenfalls dürfte jedoch nicht ein besonders hoher Druck vorliegen, wie ihn v. Recklinghausen und Meyer als Vorbedingung der Kanalbildung annehmen, eben so wenig wie in den grossen intervillösen Bluträumen der Placenta. 
Vallat beschreibt aber auch noch eine andere Genese seines kanalisirten Fibrins. Er fand direct in's Milzgewebe eingestreute Heerde, welche sich blos durch Anwesenheit von Riesenzellen als Tuberkel erkennen liessen; an diesen Heerden konnte er nun Uebergänge des Reticulums der Umgebung in das Hyalin sehen. Ersteres zeigte Verdickungen, welche gegen die fragliche Substanz zu mehr und mehr zunehmen, während eine gewisse Zahl von Zellen schwindet. Der Rest der letzteren verliert seine protoplasmatische Beschaffenheit und trägt vielleicht zur Verdickung der Balken bei, es würde also eine Trennung von Zellleib und Kern stattfinden. Es sei zum Schluss noch erwähnt, dass V allat auch eine fibröse Umwandlung von Tuberkeln beschreibt, welche im Ganzen der von uns oben als hyalin bezeichneten entspricht; es schiebt sich dann zwischen die fibröse Zone und das käsige Centrum des Tuberkels eine Partie mit kanalisirtem Fibrin ein. Hier hält Vallat ebenfalls eine directe Umwandlung des fibrösen Gewebes in hyaline Masse für möglich.

Von der von Schüppel erwähnten homogenen Umwandlung kommt hier blos die von diesem Autor als Verhorung bezeichnete Veränderung in Betracht; indess finden sich hier doch bedeutende Unterschiede. Ausserdem deutet schon die Seltenheit des Befundes (Schüppel fand die Verhornung in 40 Fällen blos einmal) darauf hin, dass bei derselben besondere Verhältnisse vorliegen.

Auch die von $W$ ieger ${ }^{1}$ ) beschriebene hyaline Substanz in den Lymphdrüsen darf wohl kaum mit unserem Fibrinoid identificirt werden. Zunächst ist zu bemerken, dass Wieger seine Befunde überhaupt nicht als "tuberculöse" auffasst, sondern als einen heerdweise auftretenden, chronisch-entzündlichen Prozess, der in den Lymphdrüsen primär sich einstellt, in anderen Organen aber metastatische Knötchen hervorruft und seine Ursache in allgemeinen dyskrasischen Verhältnissen hat. In jüngeren Stadien ergiebt sich in den Lymphdrüsen das Bild wie bei der Serofulose. Wenn es sich num auch in den Wieger'schen Fällen wohl um Tuberculose im modernen, ätiologischen Sinne gehandelt haben wird, so liegen doch jedenfalls keine ty-

1) Dieses Archiv. Bd. 78. S. 25. 
pischen umschriebenen Tuberkel vor, welche den Lymphdrüsentuberkeln ohne Weiteres an die Seite zu setzen wären. Es fehit z. B. in jenen Fällen der Ausgang in Verkäsung; Wieger giebt an, dass makroskopisch die veränderten Stellen ein diaphanes, glasiges Aussehen zeigten. Es handelt sich überhaupt blos um zwei Fälle, welche während einer längeren Periode zur Section kamen, also jedenfalls nicht um einen so gewöhnlichen Vorgang wie der der Fibrinoidbildung. Auch die Darstellung der Histogenese des Vorgangs weicht bei Wieger erheblich von unseren Befunden ab. Er constatirt in den noch am wenigsten veränderten Drüsen neben dem Auftreten zahlreicher epitheloider Zellen - ähnlich wie beim sogenannten Katarrh der Lywphdrüsen - Schwellung der Spannfasern und Verdickung des Reticulums in den Follikeln, welche ebenfalls epitheloide Zellen reichlich aufwiesen. Im Wesentlichen aber besteht, die hyaline Entartung nach Wieger darin, dass die Zellen eine homogene Umwandlung erfahren, wobei das Protoplasma derselben zum Theil sich von dem Kerne zu trenuen schien. Endlich flossen die hyalinen Massen zu Haufen von Klümpchen zusammen, welche sprung- und spaltförmige Lücken aufwiesen und in das Reticulum wie eingegossen erschienen. In den höchsten Graden der Entartung war die Masse ganz kernlos und bestand aus homogenen, ovalen oder stumpfeckigen, in ein Maschenwerk von zahlreichen, gröberen und feineren, verästelten Bälkchen eingelagerten Platten. Die Zwischensubstanz entsprach in ihrer Anordnung wiederum dem Reticulum der Lymphdrüsen, dessen Maschen stark erweitert waren und dessen Fasern aus einer zarten, längsgestreiften, kernführenden Substanz bestanden. Auch an den Gefässen fand Wieger hyaline Umwandlung, welche an deren Adventitia auftrat und ebenfalls von sklerotischem Gewebe verschieden war; er vermuthet, dass es sich um eine hyaline Entartung von Zellen handle, welche die Gefässwand infiltrirt hatten.

Es geht aus den angeführten Angaben Wieger's hervor, dass auch die Genese seines Hyalins von der unseres Fibrinoids verschieden war; seinen Ausführungen nach entstand das Hyalin der Hauptsache nach aus Zellen, neben denen auch das Reticulum mehr oder weniger gut erhalten blieb, während unseren 
Befunden zufolge den Zellen für die Fibrinoidbildung nur eine untergeordnete Rolle zukommt und auch das Reticulum nicht weiter verfolgbar hleibt. Dass andererseits das Hyalin Wieger's anch nicht mit einer sklerotischen $\mathrm{Umw}$ and lung gleichgestellt werden darf, geht aus den Angaben Wieger's hervor, in denen er dieselbe ausdrücklich von seinem Hyalin trennt.

Wenn wir also die fibrinoide Substanz weder mit dem von Wieger, noch mit dem von Vallat beschriebenen Hyalin identisch setzen können, so muss sie doch unter den allgemeinen Begriff der hyalinen Substanzen, wie er von v. Recklinghausen und von Weigert und neuerdings wieder von Lubarsch gefasst wird, subsumirt werden und zwar nach Abrechnung des vom Bindegewebe entstehenden conjunctivalen Hyalins. Bczäglich der Entstehung des Fibrinoids bleibt demnach die Frage, $o b$ es sich im Sinne Weigert's und Lubarsch's um ein exsudatives Produkt oder nach v. Recklinghausen um ein Produkt von aus den Zellen austretenden Partikeln handelt. Unsere eigenen Untersuchungen haben bezüglich dieser Genese nur wenig directe Beobachtungen ergeben. Wir konnten feststellen, dass die Zellen an der Bildung der Masse neben der Zwischensubstanz eine Rolle spielen, dass sie aber sehr bald von letzterer nicht mehr zu unterscheiden sind. Was an ihnen vorher noch bemerkbar ist, beschränkt sich, abgesehen von den Kernveränderungen, auf eine homogene oder vacuolige Umwandlung und Zerklüftung des Zellkörpers. Das Reticulum des Tuberkels liess sich beim weiteren Fortschreiten des Prozesses nicht näher verfolgen. Jedenfalls aber bilden die Zellen nicht die Hauptmasse der fibrinoiden Substanz and ebenso reicht die geringe Menge von Fibrin, welche wir im Allgemeinen feststellen konnten, nicht aus, um die Herstammung des Fibrinoids aus solchem zu erklären. Eine Betheiligung zelliger Elemente im Sinne v. Recklinghausen's, in der Weise, dass Partikel aus ihnen austreten, konnten wir für unsere Objecte, weder an den fixen Gewebszellen, noch an Leukocyten nachweisen; auch letztere erleiden keine anderen Umwandlungen als die fixen Elemente, homogene Umwandlung, Pyknose, Zerklüftung u.s.w. Es wird also blos die Annahme übrig bleiben, dass es sich um exsudatives Hyalin handelt, wobei aber von vornherein eine 
homogene Gerinnung der transsudirten Masse stattfindet; positiv spricht hiefür noch das Auftreten von Fibrin schon in frühen Stadien und gewisse Uebergänge beider letztgenaunten Substanzen, endlich die Thatsache, dass auch innerhalb von Gefässen die gleiche fibrinoide Masse vorhanden war. Naheliegend wäre es wohl auch für die Zellen, welche ja gleichfalls hyalin und schollig werden, eine Gerin ung anzunehmen, welche vielleicht Folge einer Durchtränkung derselben mit gerinnender Flüssigkeit sein könnte; damit wäre auch der in den meisten Fällen ziemlich unvermittelt sich einstellende Kernschwund gut in Uebereinstimmung zu bringen. Doch lassen sich biefür vorläufig keine positiven Gründe anführen.

Im Anschluss an die Veränderungen der umschriebenen Tuberkel, soll hier noch über gewisse eigenthümliche und diffus auftretende Veränderungen berichtet werden, welche wir in mehreren Fällen im Bereich der Stelle fanden wo die Injection der tuberculösen Masse gemacht worden war; hier, in unseren Versuchen am Oberschenkel, entwickelte sich eine diffuse Verhärtung unter der Cutis, welche bald auf die Inguinaldriisen übergriff. Bei der Section fand sich hier eine diffuse Infiltration mit Einlagerung von grauen oder gelben Knötchen neben einer ebenfalls diffusen Verkäsung, in welche meist auch die Inguinaldrüsen einbegriffen waren. Bei der mikroskopischen Untersuchung fiel hier vor Allem das diffuse Auftreten einer zelligen Infiltration und Verkäsung auf, neben welcher allerdings mehr oder minder zahlreiche, gut abgrenzbare Tuberkel sich vorfanden, welche die oben geschilderten Verhältnisse darboten. Was aber hier am meisten hervortrat, war die Ausfüllung von Gewebsspalten, offenbar Lymphspalten, mit dicht gelagerten, sehr grossen Zellen verschiedener Art. Das Gewebe zwischen den vielfach anastomosirenden Spalten zeigte gleichfalls Wucherung mit vorwiegend spindeligen Elementen. In den Hohlräumen treten unter den hier vorhandenen Zellen vor Allem oft wirklich kolossal grosse Riesenzellen hervor, von welchen viele einen mehrfach gelappten und verzweigten, grossen Kern aufwiesen. Auch die übrigen Zellen innerhalb der Spalten zeigten eine, wenn auch wechselnde, so doch im Allgemeinen bedeutende 
Grösse; ihre Form war rundlich oder zackig, sternförmig, mit mehr oder minder zahlreichen Fortsätzen; der Kern meistens rundlich bis oval und gleichfalls ziemlich gross; freilich erschienen vielfach ganz schmale, wach den Seiten spitz zulaufende Zellen mit einem entsprechend geformten, schmalen Kern; doch liess bei vielen solchen Formen, welche schief zur Ebene des Schnittes gelegen waren, durch verschiedene Einstellung der Mikrometerschraube sich der Nachweis führen, dass es sich doch um grössere, aber platte Zellformen handelte, welche blos in Folge der Schnittrichtung eine spindelige Gestalt vortäuschten. Im Allgemeinen lagen die Zellen sehr dicht, oft fast mosaikartig neben einander, doch boten sich gerade in Bezug auf die gegenseitige Lage merkwürdige Eigenthümlichkeiten dar. Zunächst sieht man öfter quer oder annähernd quer durchschnittene Hohlräume an ihrer inneren Wand mit einem circulär herumgehenden Protoplasmasaum ausgekleidet, welcher an einer oder ein paar Stellen einen Kern eingelagert enthält und an dieser Stelle meistens etwas vorgebaucht erscheint. Oefter sieht man etwa 4-5 platte, mit einander im Zusammenhang gebliebene und augenscheinlich von dem Belag der Wand herstammende Zellen von dieser abgehoben und frei in das Lumen hineinragen. Der von einer oder mehreren Zellen umfasste Hohlraum ist leer oder mit körniger Masse oder von Leukocyten oder auch von grossen epitheloiden Zellen erfüllt. Sehr auffallende Bilder geben derartige Zellen des Wandbelages, wenn in ihrem Lumen eine zweite grosse, epitheloide; oft mehrkernige Zelle eingeschlossen ist, welche dann kreisförmig von der ersteren Zelle umfasst wird. Solche Bilder kommen auch an Zellen vor, welche frei im Innern einer Spalte gelegen und von der Wand der letzteren durch Zellen anderer Art getrennt sind. Offenbar entsprechen solchen Bildern andere, wo eine grosse Zelle an einer Seite eine Einbuchtung aufweist, in welche eine zweite Zelle so eingelagert ist, dass sie, von der erstgenannten theilweise umfasst wird. Denkt man sich solche Zellen, welche in der letztbeschriebenen Ansicht in der Ebene des Gesichtsfeldes liegen, senkrecht durchschnitten, so müssen Bilder entstehen, wie sie eben beschrieben worden sind, wo eine Zelle scheinbar vollständig von einer anderen umschlossen und gleichsam in einer Vacuole der- 
selben liegend erscheint. Um die eingeschlossene Zelle herum läuft meistens ein feinerer oder breiterer Spalt, manchmal aber liegen auch die beiden Zellkörper so dicht zusammen, dass man sie kaum mehr von einander unterscheiden kann. Die ein. schliessenden Zellen sind von verschiedener Grösse und mit einem oder ein paar Kernen versehen, zum Theil grosse Riesenzellen; die eingeschlossenen, naturgemäss meistens kleineren Zellen sind im Ganzen rundlich, wenigstens was den eingeschlossenen Abschnitt betrifft, und tragen selbst wieder einen oder ein paar Kerve. Auch Leulsocyten findet man vielfach in dieser Weise eingeschlossen. Es kommen, auch von anderen Zellen, selbst dreifache derartige Invaginationen vor, indem eine eingeschlossene Zelle wiederum hohl, ringförmig, erscheint und in ibrem Hohlraum eine weitere rundliche Zelle umfasst.

Es kann wohl kaum einem Zweifel unterliegen, dass es sich hier zum allergrössten Theil um Produkte einer Endothelwucherung handelt, wobei viele Riesenzellen und Riesenzellen ähnliche Gebilde entstehen. Für eine solche Auffassung spricht die Wucherung von Zellen an der Wand der Lymphspalten oder lymphgefâsse, der manchmal noch an solchen Spalträumen vorhandene einfache Zellbelag mit Uebergängen zu mehrfachen Lagen, dann die Form nud Grösse der Zellen und die. Uebergünge zu Endothelien. Das Nähere über die Beschaffenheit der hier vorhandenen Zellen und ihrer Kerne wollen wir zusammen mit den Degenerationserscheinungen an denselben beschreiben, za welchen wir jetzt übergehen.

Die Kerne der gewucherten Endothelien, auch die der Riesenzellen, zeigen bei der Triacidfärbung ein meist sehr reichliches, grün gefärbtes Chromatingerüst, welches einem rothgefärbten Netzwerk einer Substanz anliegt, die wir mit Heidenhain als oxychromatisch, d. h. sich mit dem sauren Farbstoff tingirend, bezeichnen können. Es entspricht, wenigstens zam Theil der sonst als achromatisch bezeichneten Substanz des Kerns. Vielfach finden sich in den Kernen besonders grosse, sich rothfärbende Körner. Im Gegensatz zum Verhalten der epithelojden Zellen innerhalb des Tuberkels konnten wir hier die einzelnen Formen. der Chromatinumlagerung und Karyorrhexis in grosser Zahl nachweisen. Man findet hyperchromatische Kerne and besonders 
Kernwandhyperchromatosen; sehr vielfach Ansammlung von Chromatinbröckeln an der Kernwand, Sichelformen u. s. w., kurz alle Bilder der Kernwanddegeneration. Oft war auch die Bildung einzelner oder mehrerer grüngefärbter grober Chromatinpartikel im Innern des Kerns oder an seiner Wand auffallend. Es liegen solche mit Vorliebe in besonders grossen Kernen. Gerade hier waren die von Flemming unter dem Namen Chromatolyse beschriebenen Degenerationsformen in besonders schöner Ausbildung aufzufinden. Im Gegensatz hierzu zeigten andere hyperchromatische Kerne ein besonders zartes, feines Netzwerk von Chromatin ohne jedoch im Uebrigen von dem bekannten Typus der Hyperchromatose abzuweichen. Manche von solchen Formen hatten einen auffallend zackigen Contour. Von den mit Kernwandhyperchromatose versehenen Kernen waren manche dadurch auffallend, dass das Chromatin an die Aussenfläche gerückt, unregelmässig vertheilt und sehr feinkörnig war, während das Kerninnere fast frei von färbbarer Substanz und hiedurch sehr hell erschien, so dass der ganze Kern ein blasiges Aussehen erhielt und fast einer einzelnen Vacuole des Zellleibs glich.

Sehr häufig fand sich eine Umwandlung des Chromatins in der Art, dass die chromatischen Theile nicht mehr sich grün färbten, sondern, obwohl ihre Anordnung derjenigen der chromatischen Substanz entsprach, zuerst einen schmutzig rothgrünen, danu einen rein rothen Ton annahmen, ein Vorgang, der bei der Holzessigbehandlung und Safraninfärbung als Abblassung mit intensiv dunkelgrauer Tönung, bei der Triacidfärbung als $0 x y-$ chromasie erschien. Oft zeigten bei letzterer Tinction einzelne Partikel der Kernmembran oder des Kerninueren schon Rothfärbung, während andere noch die normale grüne Färbung beibehalten hatten. Von diesen Bildern zeigten sich Uebergänge zu. vollkommen oxychromatischen Kernen.

Kernwandsprossungen waren nicht in nennenswerther Zahl vorhanden; sehr zahlreich vertreten waren dagegen die früher von uns als Pyknose zusammengefassten Vorgänge, welche auch hier vielfach mit Oxychromasie verbunden vorkommen und schliesslich immer in letztere Veränderung ihren Ausgang nehmen. Es finden sich: (Triacidfärbung) diffus grün gefärbte, verdichtete kleine Kerne mit einigen dunkelrothen Körnern im Inneren oder 
auch mit einzelnen Vacuolen in demselben; ferner gleichmässig homogene, dichte, kleine Kerne mit intensiver Rothfärbung, ebenfalls nicht selten mit Vacuolen versehen. In einzelnen solcher liegen noch kleine bröckelige Chromatinreste. Häufig sind Wabenformen des Kerns und zwar theils grün, theils roth gefärbte, oft in unregelmässigen Formen; seltener waren die oben erwähnten Maulbeerformen.

Die Zellkörper der gewucherten Endothelien und endothelialen Riesenzellen sind sehr gross, wie die vielen Quer- und Schiefschnitte zeigen ziemlich platt, und unregelmässig geformt. Ihr Protoplasma ist körnig oder körnig-fädig, das der Riesenzellen wie in den Tuberkeln; in manchen Zellen zeigt das Protoplasma sich fein- oder grobwabig angeordnet. Von den an den Zellkörpern auftretenden $\mathrm{Umwandlungen} \mathrm{ist} \mathrm{zunächst} \mathrm{zu} \mathrm{nennen}$ eine homogene oder fädige Umwandlung, von denen besonders erstere in grosser Ausdehnung vorkommt und die Zelle im Ganzen oder an einzelnen Theilen ihres Plasmaleibes betreffen kann (Fig. 24, 28, 30). Die Veränderung geht mit einer starken Vermehrung der Färbbarkeit mit Säurefuchsin einher; dass die Veränderung den ganzen Zellkörper und nicht blos seine äusseren Schichten betrifft, oder etwa nur einer Anlagerung homogener Masse an denselben entspricht, beweisen namentlich die vielfach durchschnittenen, grossen Riesenzellen, deren Protoplasma auch zwischen den einzelnen Kernen, bezw. Kernabschnitten die homogene Beschaffenheit angenommen hat (Fig. 20). Mit Holzessig werden die homogenen Zellen dunkelgrau. Oft ist die homogene Masse von scharf begrenzten Vacuolen in grösserer oder geringerer Zahi durchsetzt (Fig. 27, 30) und sehr häufig liegen solche Vacuolen in grosser Zahl dem Kerne dicht an (Fig. 24). Manchmal ist die Vacuolenbildung so reichlich, dass der Anschein eines regelmässigen Wabenwerks entsteht (Fig. 27, 23), das dann sehr weitmaschig zu sein pflegt. Von diesen Bildern finden sich Uebergänge zu ebenfalls sehr locker gebauten Zellkörpern, deren Inneres aber eine netzige Struktur aufweist; das Netzwerk ist weniger scharf begrenzt, theilweise auch mehr oder minder körnig; in manchen Fällen wiegen grobkörnige Strukturen vor oder es finden sich in einem lockeren, dünnfädigen Netzwerk auffallend grosse, verdickte Knotenpunkte. 
An solchen Zellen, deren Kerne auch mehr oder minder oxychromatisch geworden sind, stellen sich nun weitere Veränderungen ein, welche schliesslich zum Bild des käsigen Detritus führen; es handelt sich hier im Wesentlichen um Vorgänge der Zertrennung and Zerklüftung der Zellkörper, welche vorher zu homogenen Platten zusammengelagert waren.

Ein besonders bäufiger Befund ist zunächst der, dass zwischen dem Kern und dem Zellplasma ein Hohlraum entsteht, so dass der Kern in eine Vacuole des letzteren zu liegen kommt (Fig. 27, 30). Vielleicht zieht sich im weiteren Verlauf der Kern in Folge einer Zusammensinterung vom Zellplasma hinweg oder dieses weicht nach aussen zurück. Oft finden sich mehr oder minder zahlreiche Verbindungen zwischen Kern und Zellleib, wie wir sie schon früher beschrieben haben (Dieses Archiv. 138. Fig. 61). Meist ist die Kernmembran auch an so veränderten Kernen deutlich abgrenzbar. Manchmal liegen um den Kern ganze Reihen kleiner Vacuolen; in anderen Fällen ist der erstere vollkommen frei; auch im Innern desselben liegen dann regelmässig oder unregelmässig angeordnete Vacuolen (Fig. 24, 25, 30) oder es findet sich hier auch eine dichte Netzstruktur (Fig. 26). Oft kann man an solchen, fast oder ganz oxychromatisch gewordenen Kernen die Kernmembran noch daran erkennen, dass ihr mehr oder minder zahlreiche, chromatische oder schon oxychromatische Partikel anliegen. Aehnliche Partikel finden sich dann oft auch im Innern.

In wieder anderen Fällen endlich findet blos eine partielle Umwandlung des Zellkörpers statt, indem innerhalb desselben einzelne hyaline Schollen auftreten, während die Umgebung noch körnig ist; besonders zeigen öfters die äusseren Partien der Zelle die homogene Umwandlung, während die inneren Theile noch unverändert erhalten sind. In dieser Weise zertheilt sich häufig der Zellkörper derartig in zwei Theile, dass die innere Partie von der äusseren wie von einem Ring umfasst wird und es zu einer förmlichen Schalenbildung kommt (Fig. 24, 26). An vielen anderen Zellen kommt es zu einer ganz unregelmässigen Zertheilung in amorphe Bröckel, also zu einer wirklichen Zerklüftung (Fig. 25, 31, 32). Jedenfalls ist ein grosser Theil der bei der Verkäsung vorkommenden kernlosen Platten in dieser 
Weise entstanden. Dass es sich hierbei wirklich um umgewandelte Zellen und nicht etwa blos um Zerfallsprodukte einer Zwischensubstanz handelt, geht aus den zahlreichen Uebergangsbildern, sowie auch daraus hervor, dass im Innern solcher unregelmässiger Bruchstücke vielfach noch Kerne und Kernreste erkenubar bleiben. Endlich finden sich in grosser Ausdehnung an den Kernen auch jene Veränderungen, die wir schon früher als metachromatische bezeichnet haben und deren Folge es ist, dass der Zellkörper vom Kern nicht mehr unterschieden werden kann, weil beide ganz ähnliche Strukturveränderungen erlitten haben: gleichmässig homogene Umwandlung beider oder wabige oder vacuolige Umwandlung, Zerklüftung von beiden u. s. w. (Fig. 25, 26, 31, 32).

So lange die Spalträume des Gewebes mit den dichtgedrängten Mengen wuchernder Zellen ausgefüllt sind, findet sich zwischen

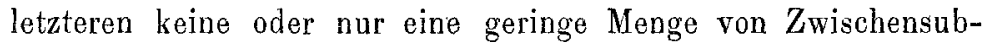
stanz. Erst mit der beginnenden Ablösung der Zellen von der Wand und von einander treten reichlichere Abscheidungen auf; dieselben zeigen sich als mit Triacid dunkelroth, fast violett gefärbte, grobe, meist an Fädchen aufgereihte Körner von unregelmässigen Umrissen, seltener stellen sie sich als gröbere $\mathrm{Fäden}$ mit unregelmässigen Anschwellungen dar. Besonders reichlich sind diese Abscheidungen gewöhnlich an den Wänden der Spalträume, suwie an den Aussenrändern der Zellen, insbesondere der Riesenzellen. Daneben finden sich sehr häufig blassere und weniger grobe, gleichfalls an Fädchen aufgereihte Körner, welche besonders bei der Färbung in Sublimat fixirter Präparate nach der Altmann'schen Methode (Israel) ${ }^{1}$ ) durch alle Uebergänge der Tinction und der Grösse zu den obigen Massen sowohl wie auch zu den, von zerfallenen Zellleibern herrührenden körnigen Gebilden überleiten. Dabei ist es, da bei der grössten Masse der erwähnten intercellulären Abscheidungen die Weigert'sche Fibrinreaction versagt, häufig nicht mehr möglich, zu unterscheiden, ob jeweils ein losgetrenter Theil eines Zellleibs oder eine zwischen. die Zellen abgeschiedene Masse vorliegt, zumal im weiteren Verlauf der Nekrotisirung sowobl die Zellleiber und ihre

1) Practicum. 1893. S. 74 , 
Zerfallsprodukte als auch die Abscheidungen ihre Färbbarkeit verlieren und mit Safranin oder Säurefuchsin-Pikrinsäure-Behandlung einen gleichmässig blassrothev, mit Holzessig einen dunkelgrauen Ton annehmen (Fig. 31, 32).

Seltener findet man in grösseren Lymphspalten eigenthümliche, fädig-körnige Gebilde, welche in Form eines Ringes in sich selbst zurücklaufen; derartige Bilder können einmal dadurch hervorgerufen werden; dass von untergegangenen Zellen (besonders Leukocyten) der Zellcontour noch erhalten bleibt und Körner irgend welcher Provenienz eingelagert enthält; ebenso kommt es vor, dass rothe Blutkörperchen, welche in die Lymphspalten gerathen sind und in denselben zu Grunde gehen, sich stark vergrössern, dabei einen scharfen' Contour und ziemlich reichliche Körner sichtbar werden lassen, die dann unter Umständen analoge Bilder erzengen; daneben bleibt aber doch ein Rest von derartig ringförmigen Zügen, welcher durch die intensive Rothfärbung, die Grösse und Unregelmässigkeit der Körner, eventuell durch den Uebergang in fädige Züge von der beschriebeaen Beschaffenheit ihre Zugehörigkeit zu den obeu genannten Abscheidungen darthun, Dass zuweilen aueh Fibrin sich in den Lymphgefässen findet, darf schon deshalb nicht Wuoder nehmen, weil sich überall geringe Mengen von rothen Blutkörperchen in den Lymphgefässen zerstreut und stellenweise auch deutliche Anzeichen von capillaren $\mathbf{H}$ ämorrhagien in die nekrosirenden Massen hinein nachweisen lassen.

Die bisher geschilderten Verhältnisse betreffen die Zellmassen innerhalb der Eingangs erwähnten, spaltartigen Hohlräume, zwischen denen bald dickere, bald dünnere bindegewebige Züge vorhanden waren. Als Ausgangspunkt für Beschreibung der in diesem. Interstitium sich einstellenden Veränderungen mag die Schilderung einer annähernd normalen, d. h. noch keine Degeneration aufweisenden Gewebspartie dienen.

In solchen Abschnitten finden sich reichliche Bündel ziemlich dichtgelagerter Bindegewebsfasern, zwischen welchen keinerlei $Z$ wischensubstanz erkennbar ist. Die Spalten des Bindegewebes sind ziemlich schmal; nur selten treten in der Längsrichtung der Fasern liegende, endotheliale Zellen hervor. Jo nachdem man es mit Quer-, Längs- oder Schiefschnitten von Bindegewebs- 
bündeln zu thun hat, zeigen die Faserdurchschnitte, Kerne und etwaigen protoplasmatischen Massen ein verschiedenes Verhalten. Auf Längsschnitten sind die Kerne länglich oval, häufig ziemlich spitz auslaufend, mit continuirlicher, wenig hervortretender, chromatischer Kernmembran, in welcher spärliche Chromatinkörner von geringer Grösse eingelagert sind; diese letzteren stehen wieder durch spärliche achromatische Fäden mit einzelnen chromatischen Körnern des Kerninneren in Verbindung. Um den Kern, namentlich an dessen Längsenden, findet sich häufig eine meist geringfügige Anhäufung einer körnigen, protoplasmatischen Masse, zuweilen auch ein etwas breiterer, dem Kern auf einer Seite anliegender Protoplasmastreifen; nach aussen schliesst sich die zumeist homogen aussehende, seltener eine Andeutung fibrillärer Streifung zeigende Substanz der Bindegewebsfaser an. Auf Querschnitten kann der von einem schmalen Protoplasmahof umgebene Kern (besonders dann, wenn auch an den Fasern die weiter unten zu beschreibenden Auflösungsvorgänge eingesetzt haben) Aulass zur Verwechselung mit Leukocyten geben, am ehesten mit solchen, welche im Beginn der Verdichtung und Verkleinerung sich befinden.

Gehen wir nunmehr zu der Beschreibung der in Degeneration befindlichen Abschnitte über, so ist zunächst von den Kernen der Bindegewebszellen zu erwähnen der Vorgang einer einfachen Abblassung (Oxychromasie) der Kerne, wobei deren Struktur keine augenfälligen Aenderungen erleidet. Die chromatischen Elemente erhalten durch die Trjacidlösung statt der grünen eine mehr schmutzig-rothgrüne Tinction, welche durch zahlreiche Uebergänge zu rein roth gefärbten Kernen überleiten. Nicht selten findet man diese totale Abblassung des Kerns zuyächst dahin modificirt, dass bei abgeblasstem Kerninneren (in welchem häufig auch noch ein grösseres, chromatisches Korn seine grüne Färbung beibehält) die Kernwand noch dunkel, schmutzig-grün gefärb̀t erscheint. Seltener sieht man die Kernwand schon abgeblasst, während im Kerninneren noch einige grosse oder mehrere kleine Körner ihre grüne Färbung beibehalten haben. Besonders hervorzuheben ist der Umstand, dass auch an den abgeblassten Kernen die Kernwand noch ausserordentlich lang als schmaler Streifen erkennbar bleibt und so die Unter- 
scheidung des Kernes von den (im Uebrigen leicht mit abgeblassten Kernen zu verwechseluden) körnigen Fragmenten von Bindegewebsfasern ermöglicht. Dass auch zu allen weiter zu beschreibenden Formen die Abblassugg secundär hinzutreten kann, braucht wohl nicht eigens erwähnt zu werden.

Häufiger als dieser erste Modus des Kernuntergangs findet sich ein anderer, bei welchem die Kerne sich in schmale, bis za $\frac{1}{3}$ oder weniger der ursprünglichen Breite reducirte, intensiv dunkelgrün gefärbte Gebilde (Triacidfärbung) sich umwandeln. Die chromatischen Körner rücken dabei sehr nahe zusammen und sind bald nicht melhr gesondert zu erkennen. Häufig sind auch Kernformen, die in der Mitte besonders schmal sind, an den beiden Enden aber hantelartig anschwellen; daneben treten weiterhia jm gleichmässig dunkel gefärbten Kernen hellere Stellen hervor, die theilweise ein vacuolenartiges Aussehen annehmen. Besonders häufig aber findet sich an den Kernen, namentlich an ihren Längsenden, eine verschiedene Anzahl (1-6) bogiger Eintiefungen; welchen je eine Vacuole anliegt; dieselbe ist nicht selten durch einen scharfen, roth gefärbten Contour gegen den übrigen Zellleib abgesetzt und birgt meist keinen oder nur einen schwach gefärbten Inhalt. Gleichzeitig mit dem Auftreten dieser Vacuolen zeigen sich zumeist schon weitere Veränderungen in der Bindegewebsfaser, indem dieselbe körnig, bröckelig erscheint; seltener sieht man in den Bindegewebsfasern Vacuolen, manchmal in so grosser Anzahl, dass die ganze Faser sich in düne Fäden aufsplitsert. Während, wie erwähnt, bei der einfachen Abblassung der Kerne die Unterscheidung derselben innerhalb der nekrosirenden Massen bald Schwierigkeiten bietet, erhalten sich diese Kerne, analog den pyknotischen Leukocytenkernen (s. u.), ausserordentlich lang und sind oft noch nach dem vollständigen Untergang der tibrigen Zelle innerhalb der nekrotischen Massen als freiliegende, dunkelgefärbte Partikel zu erkennen.

Ehe wir die Beschreibung der Veränderungen in den interstitiellen Bindegewebszügen abschliessen, müssen noch zwei andere, im Interstitium vorkommende Bestandtheile aufgeführt werden, deren Herstammung wicht an allen Stellen leicht zu beurtheilen ist. Da sind zunächst schon in wenig verändertem Gewebe, in zunehmender Menge aber in den in die nekrosirenden Partien 


\section{1}

übergehenden A bschnitten, sandig-körnige Massen enthalten, welche im Allgemeinen mit den innerhalb der Lymphspalten gelegenen übereinstimmen. Hier bilden sie theils Haufen oder Reihen rundlicher Körner. $z$ wischen den Bindegewebszügen oder liegen auch auf längere Strecken hin den Fasern derselben sehr dicht an. Ihre Färbung ist manchmal (Triacid) sehr dunkel roth, manchmal aber auch nicht intensiver als die der Bindegewebs. fasern. Häufiger noch sind zahlreiche solcher Körner an einander gereiht, welche sich von Bindegewebsfibrillen mit dicht anliegenden Körnchen einmal durch die grössere Ungleichmässigkeit der Faserdicke, besonders aber durch die Einlagerung wenigstens eines Theiles der Körner in die Fäden unterscheiden. Solche fädig-körnige Züge liegen besonders auch in den die Spalträume unmittelbar begrenzenden Gewebstheilen und stehen auch des öfteren mit ähnlichen Massen innerhalb jener Spalten in Verbindung. Trotzdem entstehen oft Schwiorigkeiten, diese Elemente. von Produkten des zu Grunde gehenden Bindegewebes aus einander zu halten, wenn im weiteren Verlaufe auch die Bindegewebsfasern theils zu gröberen und kleineren Bröckeln und Körnern zerfallen, theils in feinste Fibrillen sich aufspalten, die ihrerseits in der gleichen Weise eine Zerklüftung erleiden. Immerhin sind wenigstens die grösseren, dunkler gefärbten Körner und Fäden auch innerhalb der nekrotischen Massen häufig noch ziemlich lange nachzuweisen.

Es kann sich nach dem Gesagten in den beschriebenen Gebilden, hier wie in den Spalträumen, wohl um nichts Anderes als um Ausscheidungsprodukte plasmatischer Flüssigkeit handeln. Doch liegt auch keinesfalls Fibrin im gewöhnlichen Sinne vor, da die Gebilde die Fibrinreaction nirgends geben. Dagegen ist hervorzuheben, dass dieselben bei der Säurefuchsinfärbung eine auffallend ungleichmässige, tiefrothe Färbung aufweisen; gleichzeitig findet man bei letzterer Färbeweise Uebergänge von stark roth gefärbten zu mehr gelbrothen und schliesslich rein gelben Fäden und Körnern von sonst gleicher Beschaffenheit, welche entweder als weitere Umwandlungsprodukte der roth gefärbten Massen oder als gleichwerthige, transsudirte Massen angesehen werden müssen. Besonders mit der genannten Methode lässt sich auch die zunehmende Reichlichkeit dieser 
Gebilde mit dem fortschreitenden Untergang der zelligen Elemente verfolgen. Auch in den nekrotischen Massen erbält sich die rothe Färbung noch ziemlich lange, macht aber allmählich einer gelben Platz.

Bei der Färbung nach van Gieson sind sowohl die Fäden, als die Körner gelb oder leicht gelbroth gefärbt. Dieselben haben in Bezug auf ihre Form und Färbung eine gewisse Aehnlichkeit mit den bei der Beschreibung des Tuberkels erwähnten fibrinoiden Massen und dürften wohl einem analogen Vorgang ihre Entstehung verdanken.

In zweiter Linie ist hier einer eigenthümlichen Umwandlung der bindegewebigen Septa zu gedenken, welche zunächst sich hauptsächlich auf die Ränder der Lymphspalten erstreckt, weiterhin aber die ganze Breite der Balken einnehmen kann. An Stelle der fibrillären Zeichnung treten dabei auf den ersten Blick vollkommen homogen aussehende Streifen und Bänder auf; dieselben färben sich mit der Ehrlich'schen Triacidlösung roth, zumeist jedoch weniger intensiv als das andere Bindegewebe: mit der van Gieson'schen Färbung zeigen sie gleichfalls einen fuchsinrothen Ton; bei der Färbung in Sublimat fixirter Schnitte mit Säurefuchsin und nachfolgender Differenzirung mit Pikrinsäure (Israel) erscheinen sie gelb gefärbt. Häufig sieht man in die Streifen homogener Masse hinein die Bindegewebsfasern in mehr oder weniger lockere feinste Fibrillen aufgespalten. Auch in den anscheinend homogenen Massen gelingt es mit starken Vergrösserungen sehr häufig eine Anzahl feinster Fibrillen nachzuweisen, welche meist parallel laufen, zum Theil aber auch sich in grösseren Bündeln durchkreuzen; in anderen Fällen sieht man zwar bei jeder Einstellung eine Lage scharf gezeichneter, dicht gedrängter Fibrillen, daneben bleibt aber eine verwaschene, die $Z$ wischenräume ausfüllende rothe Färbung übrig, welche mit grösster $W$ ahrscheinlichkeit auf die leichte Zerstreunng durch die tiefer und höher liegenden, nicht eingestellten FibrillenJagen zurückzuführen ist. Bei der Färbung nach van Gieson lassen sich $z$ wischen den rothen Massen vielfach braune und gelbe Körnchen erkennen, welche wohl den vorhin beschriebenen Produkten der Transsudation entsprechen.

Gegen die nekrotischen Heerde zu werden die homogenen 
Bänder im Allgemeinen seltener; in den nekrotischen Partien sind auch sie zumeist in Auffaserung und körnig-bröckeligem Zerfall begriffen; bei der Färbung nach van Gieson sieht man zuweilen eines dieser roth gefärbten Bänder an eben der Stelle, wo es in die nekrotischen Massen hereinragt, in eine scharf abgesetzte, gelb gefärbte Masse übergehen.

Es fragt sich nun, ob wir es in den letztbeschriebenen homogenen Massen mit einem Produkt einer Transsudation oder einer Bindegewebsumwandlung oder vielleicht mit einer Combination beider Vorgänge zu thun haben.

Für die erstere Möglichkeit kann die Thatsache angeführt werden, dass an anderen Stellen (s. o.) das Vorkommen eines Transsudats als erwiesen angenommen werden darf, sowie der Umstand, dass in vielen Fällen die Zerlegung der homogenen Streifen in einzelne Fibrillen nicht gelingt. Dabei erscheint es aber auffällig, dass in jenen Abschnitten das Bindegewebe so plötzlich von der Bildfläche verschwindet. Oft sieht man noch deutlich Bindegewebszüge in die homogene Masse einstrahlen und auf der anderen Seite eben solche Bindegewebszüge aus derselben austreten, ohne dass in der Breite des Septumbalkens eine auffällige Veränderung eingetreten wäre. Da nun die ganze Masse vollkommen gleichmässig in der Farbe und Form erscheint, so müsste nothwendig angenommen werden, dass das eventuell vorhandene homogene Transsudat mit dem umgewandelten Bindegewebe vollkommen gleiche Lichtbrechung, Färbbarkeit und Gestaltung erhalten habe. Was speciell den letzteren Punkt anlangt, so scheint namentlich die vielfach mögliche Zerlegung der ganzen Masse in vollkommen gleichmässige Fibrillen gegen die Annahme zu sprechen, dass eiver homogenen Transsudation die Hauptrolle bei der Entstehung solcher Bilder zukomme, und es muss eher die Betheiligung des Bindegewebes an dem Zustandekommen der homogenen Massen in den Vordergrund gestellt werden. Wir haben schon oben hervorgehoben, dass an den Bindegewebsfasern häufig eine Aufspaltung in Mengen dünnster, primitiver Fibrillen stattfinde und es erübrigt zu bemerken, dass diese letzteren Gebilde in Bezug auf Dicke, Färbbarkeit und Lagerung den vorhin als Bestandtheile der homogenen Massen geschilderten Fibrillen ganz oder fast vollständig entsprechen; 
es dürfte sich sonach am wahrscheinlichsten um eine Aufnahme von Flüssigkeit zwischen die Fibrillen der Bindegewebsfasern und eine daraus resultirende gleichmässige Auseina nderdrängung derselben handeln, wobei es allerdings auffällig bleibt, dass die Fibrillen selbst, zunächst wenigstens, keine Aenderung in ibrem physikalischen Verhalten zu erfahren scheinen. Man kann weiterhin denken, dass die aufgenommene Flüssigkeit bald mehr einer einfachen Salzlösung sich nähere, bald grössere Verwandtschaft mit der Zusammensetzung des Blutplasmas behalten habe und je nach der angewandten Färbungsmethode dem Nachweis zugänglich geblieben sei oder sich demselben entzogen habe. Indessen möchten wir auf derartige hypothetische Vorstellungen kein weiteres Gewicht legen und nur die Möglichkeit betont haben, dass auf diesem Wege vielleicht die doppelte Herkunft der homogenen Massen eine Erk]ärung finde.

Nach den im Vorausgehenden gemachten Angaben ist äber das weitere Verhalten des Interstitiums bei der Nekrose nicht viel mehr anzufügen.

Es wurde schon hervorgehoben, dass bis zu einem gewissen Zeitpunkt die Abscheidung körnig-fädiger Massen zunimmt, dass weiterhin das Bindegewebe selbst in gröbere und feinere Körner zerfällt, welche von ersteren vielfach nicht mehr unterschieden werden können, zumal auch sie sich vielfach an noch stehen gebliebene Fasern dicht auflagern. Die sämmtlichen. Bestandtheile des Interstitiums erscheinen schliesslich als eine, von wenigen groben, mit Triacid roth gefärbten Fasern durchzogene Masse, welche allerorts ohne. scharfe Grenze in die nekrotischen Theile der Lymphräume übergeht und mit diesen eine gemeinsame, aus gröberen und feineren Körnern, Schollen, Faserbruchstücken, Kernresten u. s. w. zusammengesetzte Detritusmasse bilden.

Es seien hier noch ein paar Worte über die auch im Bereich der diffusen Wucherungen an der Injectionsstelle, und zwar sowohl in den Spalträumen, wie in den Interstitien, reichlich vorhandenen Leukocyten angefügt.

Die Veränderungen, welche dieselben in diesen verkäsenden Gebieten erfahren, sind im Wesentlichen von dreierlei Art. Zanächst findet sich sowohl an den einkernigen als an den so- 
genannten mehrkernigen Leukocyten in ausgeprägter Weise dië Chromatolyse im Flemming'schen Sinne; schon in den Gefässen beobachtet man zuweilen Kerne, deren Chromatin sich an der Kernmembran in Form eines Ringes, Halbmondes oder einiger schalenartiger Verdickungen von gleichmässig intensiver Färbung angesammelt hat, während im Kerninneren sich höchstens noch Spuren von Chromatin in Form einzelner Körnchen finden; meist enthält der Kern nur spärliche achromatische Fäden, seltener eine Anhäufung von mit Fuchsin sich färbenden, gröberen oder feineren Körnern (Heidenhain's Lauthaninglobulus), endlich ist in einzelnen Kernen das ganze Innere ausgefüllt mit einer intensiv dunkelroth gefärbten, eine körnige Struktur zeigenden, oder - häufiger - ganz homogen erscheinenden Masse. In den nekrotischen Partien verschwinden diese Kernformen ziemlich rasch, indem sie einer einfachen Abblassung und Auslaugung anheimfallen.

Als einen zweiten Typus des Leukocytenuntergangs können wir eine der Pyknose ähnliche Veränderung beschreiben, bei welcher die äussere Hälfte des Kerns von einer diffus grün, bezw. roth (Triacid, bezw. Flemming'sche lösung) gefärbten Masse eingenommen ist, welche im Inneren nur wenige zusammengeballte, tief rothe (bezw. dunkelgraue) Körner dicht umschliesst. Sehr häufig finden sich an der Oberfläche dieser Kerne die schon an anderer Stelle beschriebenen Vacuolenbildungen des Zellleibs; ferner sieht man diese Kerne häufig noch innerhalb sonst in Nekrose übergegangener Zellhaufen, wobei der Zellleib meist mehr oder weniger vollständig in das Gerinnsel, welches zwischen den Zellen sich findet über- und aufgegangen ist. Die weiteren Veränderungen dieser Kerne bestehen entweder in Abblassung (Oxychromasie) oder in zunehmender Verdichtung und Verkleinerung, an welche erst später sich die Entfärbung anschliesst. Ihrem ganzen Aussehen nach stellen diese Kernformen, welche übrigens ähnlich auch an Lymphgefässendothelien beobachtet werden, eine Mittelform dar zwischen der Chromatolyse (Ansammlung des Chromatins an der Oberfläche, des Achromatins im Innern) und der eigentlichen Pyknose, zu welch' letzterer sie wegen der vorwiegenden Verdichtung, Sinterung, wohl noch eher zu stellen sind. Die eigentliche Pyknose, 
welche demgemäss von der eben beschriebenen Form nicht scharf abgetrennt werden kann, bietet in ihrem Auftreten nichts vom gewöhnlichen Verhalten Abweichendes. Abblassung endlich kann sowohl an den in ihrer Struktur noch unveränderten Leukocyten, wie in irgend einem Stadium der genannten Veränderungen einsetzen.

Für die polymorphen und fragmentirten Kerne der Leukocyten können als hauptsächliche Degenerationsformen gleichfalls Pyknose und Kernwanddegeneration von der Art der Chromatolyse namhaft gemacht werden; daneben finden sich auch an der Injectionsstelle die schon früher erwähnten Umwandlungen der Kerne in reichliche, kleine-Bläschen, die weiterhin sich entfärben, zerfallen u. s. w.

Für die mit einfachem rundlichem Kern versehenen weissen Blutkörperchen wird es mit der zunehmenden degenerativen Veränderung ziemlich schwierig, sie von den veränderten Endothelien, ja zuweilen sogar von Bindegewebszellen zu unterscheiden. Da wie an den übrigen Stellen, so auch im Bereiche der Injectionsstelle die Leukocyten andauernd reichlich zuwandern und verhältnissmässig lange sich erhalten, so muss auch hier von den in den nekrotischen Massen enthaltenen Kernen ein grosser Theil denselben zugerechnet werden.

Die Genese des käsigen Prozesses im Bereich der diffusen Wucherungen der Injectionsstelle mit ihren Endothelwucherungen stimmt also nicht völlig mit dem überein, was wir an den Tuberkeln der inneren Organe gesehen haben, obwohl gerade an den diffus veränderten Stellen die Verkäsung makroskopisch leicht mit Sicherheit festzustellen war. An beiderlei Stellen, den diffusen Wucherungen wie den umschriebenen Tuberkeln, ist dem Vorgang gemeinsam ein Absterben der zelligen Elemente, wie des Gewebes überhaupt, und das Auftreten einer intercellalären, wahrscheinlich von einem Transsudat herstammenden, fest werdenden $Z$ wischensubstanz, neben einer, im Ganzen und Grossen spärlichen Abscheidung typischen, faserigen, die charakteristische Reaction gebenden Fibrins. Im Einzelnen aber finden sich Verschiedenheiten; im Tuberkel findet man die Zwischensubstanz sehr reichlich und 
frühzeitig, und zwar zum grossen Theil in einer Form, welche der des Langhans'schen kanalisirten Fibrins nahe steht. Ein Absterben der Zellen vor dem Auftreten dieser Substanz ist nur an verhältnissmässig wenigen Stellen nachzuweisen; es scheint vielmehr, dass beide Vorgänge ziemlich gleichmässig erfolgen. Die abgeschiedene Substanz, welche wir, lediglich um nichts zu präjudiciren, als Fibrinoid bezeichnet haben, steht ihrer Genese nach wohl dem typischen Fibrin nahe, ist aber nicht mit demselben identisch. Zur Bildung derselben tragen auch die absterbenden Zellen bei, wenigstens gehen sie in der Bildung derselben auf. Dass aus den Kernen das Chromatin in ausgedehntem Maasse und, wie es scheint, ziemlich plötzlich verschwindet, würde am besten mit der Annahme einer Durchströmung derselben und einer Auslaugung des Chromatins übereinstimmen. Durch das rasche Schwinden des Chromatins und das spärliche Vorkommen von Umlagerungsprozessen desselben jnnerhalb der absterbenden Kerne unterscheidet die Verkäsung der Tuberkel sich wesentlich von der einfachen anämischen Nekrose, wie sie z. B. als Folge von Absperrung der Blutzufuhr sich einstellt. Im weiteren Verlauf erfolgt die Bildung eines käsigen Detritus durch eine fortschreitende Zerklüftung der fibrinoiden Substanz, nachdem, wie erwähnt, die Zellen schon vorher in derselben mit aufgegangen waren.

Im Bereich der diffusen Gewebswucherungen an der Injectionsstelle ist ebenfalls das Auftreten einer, wahrscheinlich aus einem Transsudat herstammenden Zwischensubstanz zu erkenuen; doch tritt die letztere hier nicht unter dem Bild des kanalisirten Fibrins auf, sondern mehr in körniger bis körnig-fädiger Form. Wenn nun hierin auch ein principieller Unterschied - auch in den Tuberkeln finden sich Anfangs feinkörnige Niederschläge zwischen den Zellen — nicht gesehen werden darf, so ist doch andererseits hervorzuheben, dass an diesen Stellen die absterbenden Zellen auch räumlich weitaus das Vorwiegende sind, und dass der Zwischensubstanz nicht, wie in den Tuberkeln, eine Hauptrolle bei der Bildung der käsigen Partien zugesprochen werden darf. Dieselben bestehen an diesen Stellen vielmehr vorzugsweise aus Zellen, bezw. Bindegewebsfasern und deren Zerfallsprodukten. 
Nachdem also schon bei ein und derselben Thierart an verschiedenen Organen eine Verschiedenheit in der Genese dos käsigen Prozesses vorhanden ist, wird es angezeigt sein, zunächst von Verallgemeinerungen der aus unseren Befunden sich ergebenden Schlüsse abzusehen; es wäre sehr leicht denkbar, dass der käsige Prozess bei anderen Thierarten und bei anderer Aetiologie noch grössere Abweichungen aufweist. Wir möchten daher - ausschliesslich mit Beziehung auf die uns vorgelegenen Objecte - vorläufig blos so viel sagen, dass bei der Verkäsung neben dem Absterben der Zellen das Auftreten einer aus dem Blutherstammenden und wahrsheinlich dann erstarrenden Transsudationsmasse eine wichtige Rolle spielt, dass diese Masse unter verschiedenen Formen, zum Theil unter der des kanalisirten Fibrins, also einer hyalinen Form auftritt, und dass dieselbe wahrscheinlich eine Hauptursache der festen, trockenen Beschaffenheit der käsigen Massen darstellt. Mit der Massenhaftigkeit des Auftretens dieser Zwischensubstanz geht ein ausgedehntes, rasches Schwinden des Chromatins der Zellkerne parallel, was, wie erwähnt, am ehesten als Folge einer Auslaugung desselben (vor Eintritt der Gerinnung der Flüssigkeit) zu erklären wäre. In Uebereinstimmung damit sind die Bilder der Karyorrhexis und verwandter Degenerationsformen bei der Verkäsung viel spärlicher als bei der einfachen anämischen Nekrose ${ }^{1}$ ).

1) Als Analogon zu der von uns angenommenen Abscheidung eines gerinnenden, homogenen oder hyalinen Transsudats können wir die Befunde von Leusden anführen, welcher bei puerperaler Eklampsie in den Ajveolen der Lunge ähnliche, dieselben bandartig auskleidende Massen fand, welche wahrscheinlich mit hyalinen Thromben innerbalb der Gefässe in Beziehung standen und gleichfalls die Fibrinreaction nicbt gaben (Dieses Archiv. Bd. 142. S. 1). Auch im Falle Leusden's konnte es sich nicht um fertig gebildetes, etwa homogen umgewandeltes Fibrin bandeln, da die Massen offenbar ganz frisch entstanden waren, wie die von ibnen eingeschlossenen, noch gut erbaltenen Epithelien bewiesen. Aehnliche Bilder wurden schon vorher von Schmorl beschrieben. Auch Leusden nimmt an, dass die Massen durcb Exsudation aus den Gefässen entstanden seien. Wir haben in letzter Zeit äbnliche Ausscheidungen in ein paar Fällen von käsiger, mit starker Fibrinabscheidung combinirter Pneumonie gefunden. Noch auffallender ist es vielleicht, dass wir auch körnige und körnig- 
Zur Entscheidung der Frage, ob es sich bei der Verkäsung um eine Coagulationsnekrose oder um Inspissation handelt, müsste noch weiteres Material beigebracht und der Vorgang bei verschiedenen Thierarten und verschiedenen Krankheitsprozessen untersucht werden. Dass neben der Gerinnung einer Zwischensubstanz auch noch eine solche der abgestorbenen Zellen (im Sinne Weigert's) stattfindet, konnten wir nicht nachweisen, doch würde eine solche Annahme mit den übrigen Befunden gut übereinstimmen. Andererseits konnten wir auch nicht ausschliessen, dass etwa bei der zur späteren Detritusbildung führendẹn Zerklüftung der abgestorbenen Massen einer Inspissation, d. h. einer Schrumpfung derselben durch Wasserverlust, eine Rolle zukomme. Dagegen geht unseres Erachtens aus unseren Befunden hervor, dass der Beginn des Prozesses nicht auf eine solche Wasserabgabe und Schrumpfung zurückgeführt werden darf. Damit stimmt auch die anfänglich vorhandene Vergrösserung verküsender Partien überein.

Ebenso könnte blos durch weitere Untersuchungen die Frage beantwortet werden, ob nicht für den makroskopischen Begriff der Verkäsung, der ja ein sehr wenig scharf begrenzter ist, eine auf histologische Merkmale begründete Definition gesetzt werden müsse, etwa im Sinne Israel's, welcher den Begriff der Ver-

fädige Massen begegneten, welche die Weigert'sche Fibrinreaction nicht gaben, dagegen zum grossen Theile wenigstens nach der von Israel für die Darstellung von Fibrin empfoblenen Altmann'schen Färbung (nach der Altmann'schen Fixirung oder beliebiger anderer. Fixation, vergleiche Israel, Die anämische Nekrose der Nierenepithelien. Dieses Archiv. Bd. 123. S. 322 und Practicum der patbologischen Bistologie. S. 74) noch färbbar waren. - Nacbdem wir zablreiche Versuche mit der Weigert'schen Fibrinfärbung angestellt haben, erscheint es uns ausgeschlossen, dass es sich um einen Fehler bei der Behandlung der Präparate gebandelt habe. Jedenfalls entfärbten die genannten Massen sich viel leichter und früber, als der typische Faserstoff, wenn sie auch dem letzteren wohl sehr nahe stehen. Andererseits deutet die Färbbarkeit eines Theiles derselben mit der von Israel empfohlenen Methode darauf hin, dass sie Uebergänge zu dichteren, mehr bomogenen, hyalinen Massen bilden, wie es ja auch homogene Massen giebt, welche sich mit der Weigert'schen Fibrinfärbung blau tingiren (Lubarsch, Manasse u. A.), ohne mit dem Fibrin gerade identisch zu sein. 
käsung an die amorphe, „geschrumpfte ${ }^{\text {s6 }}$ Zelle anschliessen lässt. Es würde sich hier im Wesentlichen darum handeln, ob man die den Prozess einleitende Fibrinoidbildung bereits zur Verkäsung rechnen will, oder in dieser blos ein Vorstadium sieht, dem eine ächte Verkäsung vielleicht gar nicht mit Nothwendigkeit zu folgen hat. An den Tuberkeln tritt die Fibrinoidbildung schon so frühzeitig ein, dass man das ganze Koötchen makroskopisch noch gar nicht wahrnehmen kann und es daher unmöglich ist zu entscheiden, ob diese fibrinoidhaltigen Partien bereits makroskopisch den Eindruck einer käsigen Masse machen würden, während an grösseren, sichtlich verkästen Tuberkeln immer auch schon körniger Detritus in reichlicher Menge vorhanden ist. Von den diffusen Verkäsungen des subcutanen Gewebes können wir allerdings sagen, dass auch an makroskopisch deutlich verkästen Stellen mikroskopisch noch an vielen Partien die Detritusbildung fehlte, doch waren dieselben viel zu sehr mit körnig zerfallenen Stellen vermischt und durchsetzt, um ein sicheres Urtheil hierüber zu gestatten. Endlich möchten wir noch die Frage offen lassen, ob nicht das Fibrinoid und ihm verwandte Abscheidungen, ohne einen weiteren Zerfall zu erleiden, dauernd bestehen bleiben und als solche in eine oder die andere Art der formenreichen Gruppe der Hyaline übergehen kann.

\section{Erklärung der Abbildungen.}

Tafel II und III.

Die sämmtlichen Figuren stammen von Präparaten, welche mit Hermann'scher Flüssigkeit und Holzessig vorbebandelt und mit Safranin gefärbt waren. - Vergrösserung, wo nichts Anderes angegeben: Zeiss Apochrom. 2/1,30. 0cul. 8.

Fig. 1. Epitheloide Zelle mit wabigem Bau und mässig chromatinreichem Kern. In letzterem das Chromatin in Körnchen einem Liningerüst und einem Nucleolus angelagert.

Fjg. 2. Zelle mit einem diffus gefärbten, feinkörnig-hyperchromatischen Kern.

Fig. ล. Lymphoide Rundzelle mit chromatinreichem, leicbt diffus gefärbtem Kern.

Eig. 4. Langgezogener, biscuitförmig eingeschnürter Kern mit leichter Diffusfärbung. Chromatinkörner im Allgemeinen der Längsrichtung des Kerns entsprechend orientirt.

Fig. 5 und 6. Hyperchromatische Kerne, der Grösse nach zwischen denen der epitheloiden Zellen und der Rundzellen stehend. 
Fig. 7. Kleiner, mit blossem Auge noch nicht sichtbarer Tuberkel der Leber. Bei a Züge von Bindegewebe an der Peripherie, hier wenig ausgeprägt. ' b dem Tuberkel anliegender Gallengang mit etwas Bindegewebe umgeben. c feine, scharf begrenzte Fasern des $R e-$ ticulums. $d, d_{1}$ und $c, c_{1}$ theils feineres, theils gröberes Gerinnsel (Fibrinoid), Anfangs deutlich $\mathrm{z}$ wiscben den Zellen liegend, bei e und $e_{1}$ auch grössere, zum Theil rundliche Klumpen. f feiner, mit einem doppelten Contour versehener Spalt, einer Capillare (?) entsprechend. $g$ mittelstarke, dunkle, leicht längsgestreifte interstitielle Züge (collabirte Capillaren?), die an anderen Stellen in offene Capillaren äbergeben. Im Centrum des Taberkels ist das Reticulum grossentheils durch das Fibrinoid verdeckt; die Zellen sind theils kernlos, theils schon ganz zu Grunde gegangen. Von Kernen sind im Tuberkel die verschiedenen oben angefübrten Formen zu erkennen. (Seibert, $\frac{1}{12}$, Oc. I.)

Fig. 8-11. Pyknotische Kerne. 8 und 9 noch diffus gefärbt, aber schon in Verdichtung mit dunkelgrauem Grundton (Holzessig). 10 nahezu, 11 ganz chromatinlos gewordener Kern. Letzterer durch einen Spalt rom Zellkörper abgetrennt.

Fig. 12. Hyperchromatischer Kern mit auffallend dicker, chromatischer Kernmembran. Der Zelle liegen nach aussen feine, fädige, nach W eigert sich nicht färbende Gerinnsel an.

Fig. 13. Pyknotischer Kern mit Wabenform.

Fig. 14. Aehnlicher Kern mit Auffaserung: am Rande.

Fig. 15. Hyperchromatischer Kern wit längsgestellten Chromatinpartikeln.

Fig. 16 und 17. Dem Reticulum angehörige Zellen mit dunklem, homogenem Zellkörper.

Fig. 18. Riesenzelle aus einem Lebertuberkel, mit Ausläufern versehen; rechts liegen der Zelle dichte, gerinnselartige Massen an. Die Kerne ähnlicb, wie diejenigen der Epitheloidzellen (Fig. 1). Das Zellinnere theils körnig, theils wabig, an einer Stelle sehr dicht, fast homogen.

Fig. 19 und 20. Riesenzellen aus Lebertuberkeln. Letztere Zelle mit ausgesprocben wabigem $\mathrm{Bau}$, an ersterer eine wabig gebaute, hellere Aussenschicht.

Fig. 21-23. Riesenzellen aus den diffusen Endothelwucherungen der Injectionsstelle. Fig. 22 mit wabigem, pyknotischem Kerne, dem eine Vàcuole anliegt. Fig. 23 Riesenzelle, welche eine zweite, pyknotische und mit pyknotischem Kern versehene Zelle einscbliesst. Der Kern der einschliessenden Zelle mit einem grossen Nucleolus. Fig. 21 grosse Riesenzelle mit bomogen gewordenem, dunklem Zellleib; die Kerne theils hyperchromatisch, theils schon pyknotisch.

Fig. 24-32. Metachromatische Veränderungen an Zellen der diffusen Endothelwucherung.

Fig. 24. Scbalenförmige Absprengung an der äusseren Partie des Zellleibs. 
Fig. 25. Wabiger, chromatinloser Kern von unregelmässigen Fragmenten umgeben, deren Berstammung - ob aus Zellfragmenten oder Gerinnseln - nicht mebr entschieden werden kann.

Fig. 26. Trennung von Kern und Zellkörper, bezw. der inveren, nunmehr kernlos gewordenen und der ausseren Schicht des Zellkörpers.

Fig. 27. Metachromatische Umwandlung zweier Zellen, der invaginirten, wie der sie umschliessenden.

Fig. 28. Wabige Umwandlung des centralen, früher kernhaltigen Theiles der Zelle.

Fig. 29. Mehrfach verästelte Zelle wit noch erkennbarem, grosse achromatische Partikel enthaltendem Kern.

Fig. 30. Umschliessende Zelle mit homogen gewordenem, mit Vacuolen durchsetztem Zelleib und invaginirte Zelle mit bellem Plasmaleib und grobwabigem Kern. An der rechten Seite der letzteren Zelle ein feiner Spalt.

Fig. 31 und 32. Aus vollkommen verkästen Stellen entnommene Partien, zum Theil aus Zellresten mit noch erkennbaren Kernresten, zum Theil wobl auch aus Gerinnselmassen bestehend.

Fig. 33-38. Untergangsformen von Leukocyten, die zum Theil ( 36 und 37 a) in andere Zellen eingeschlossen sind. Man sieht dunkel gefärbte und schon abgeblasste, pyknotische Kerne (Fig. 33, 36), Kernwandhyperchromatosen wit Schalenbildungen $(35,37,36)$ und Gitterformen $(34,38)$. 